University of the Pacific

Scholarly Commons

University of the Pacific Theses and

Dissertations

Graduate School

1988

\title{
A comparative analysis of comprehension questions in three California state-adopted Spanish and English basal readers
}

Ana Maria Bonilla

University of the Pacific

Follow this and additional works at: https://scholarlycommons.pacific.edu/uop_etds

Part of the Education Commons

\section{Recommended Citation}

Bonilla, Ana Maria. (1988). A comparative analysis of comprehension questions in three California stateadopted Spanish and English basal readers. University of the Pacific, Dissertation.

https://scholarlycommons.pacific.edu/uop_etds/3205

This Dissertation is brought to you for free and open access by the Graduate School at Scholarly Commons. It has been accepted for inclusion in University of the Pacific Theses and Dissertations by an authorized administrator of Scholarly Commons. For more information, please contact mgibney@pacific.edu. 
A COMPARATIVE ANALYSIS OF COMPREHENSION QUESTIONS IN THREE CALIFORNIA STATE-ADOPTED SPANISH AND ENGLISH BASAL READERS

\author{
A Dissertation \\ Presented to \\ the Faculty of the school of Education \\ University of the Pacific
}

\begin{abstract}
In Partial Fulfillment
of the Requirement for the Degree

Doctor of Education
\end{abstract}

By

Ana Maria Bonilla

April 20, 1988 
This dissertation, written and submitted by

Ana Maria Bonita

is approved for recommendation to the Committee

on Graduate Studies, University of the Pacific

Dean of the School or Department Chairman:

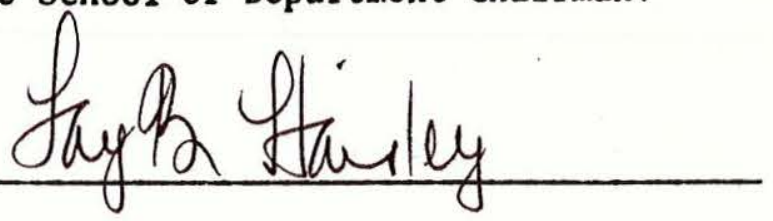

Dissertation Committee:
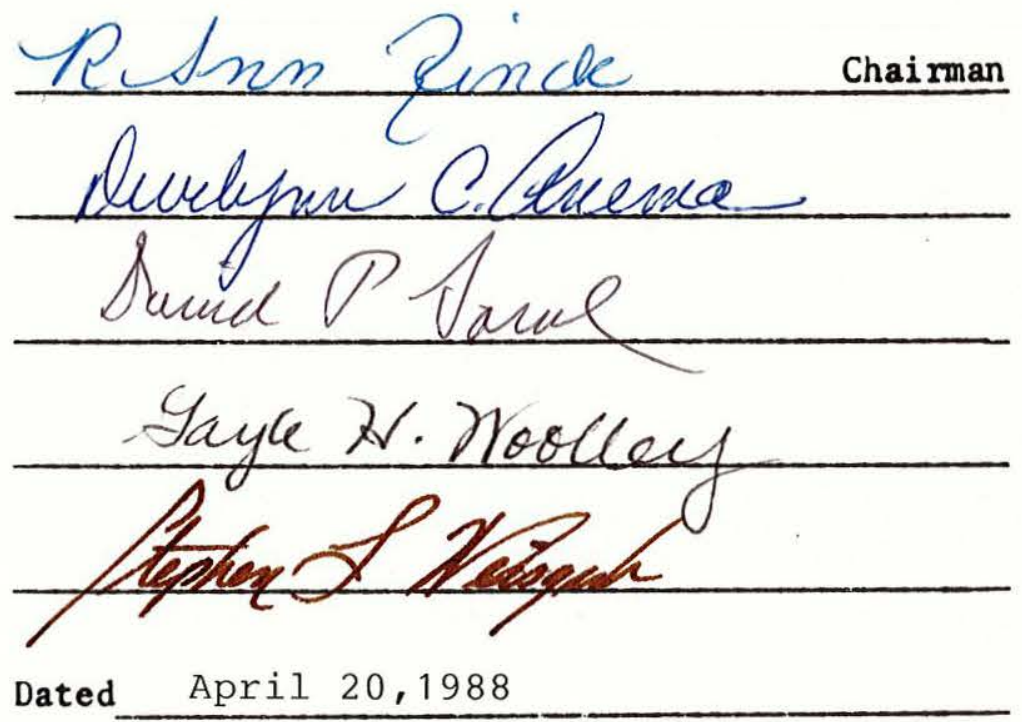
(C) Copyright, 1988

Ana Maria Bonilla

All Rights Reserved

April 20, 1988 


\section{ABSTRACT}

\section{A COMPARATIVE ANALYSIS OF COMPREHENSION QUESTIONS \\ IN THREE CALIFORNIA STATE-ADOPTED SPANISH \\ AND ENGLISH BASAL READERS}

\section{Ana Maria Bonilla}

The primary purpose of this study was to determine if there was a variation in the number of questions within a given taxonomy level between parallel Spanish and English basal readers at primary grade levels. A secondary purpose was to determine if questions in parallel Spanish and English series, that extended to fourth grade, facilitated the transition from the Spanish to the English reader. Specifically, the tasks to be accomplished in the study were: (1) to classify reading questions contained in California state-adopted parallel Spanish and English basal readers utilizing Barrett's Taxonomy, (2) to determine the number of questions each level of the taxonomy contained, (3) to determine if the number of questions within each level of the taxonomy differed by reading series among grade levels and between languages, and (4) to ascertain the readability level of each reader utilized in this study.

Three California state-adopted parallel spanish and English basal series were selected. A total of 114 lesson plans: fifty-four from the Spanish series and sixty from the English series, were selected. A total of 5,797 reading 
comprehension questions were classified according to the four major divisions of the Barrett Taxonomy.

Chi Square values revealed that differences do exist on the number of questions assigned to each taxonomy level among the three basal series in both languages. Chi Square values also revealed that differences do exist on the number of questions assigned to each taxonomy level between the basal series at the first, second, and third grade level. At all grade levels, and in both languages, literal level questions were highest in frequency and percentage, followed by inference, evaluation, and appreciation level questions respectively. These findings seem to indicate that there is a tendency among basal readers, to emphasize questions which require literal comprehension more than critical interpretation. Differences were also found in the readability level between the Spanish and English text at each grade level. All readers, with the exception of the first grade English readers, were above the stated reading level and in most cases the readability level of the Spanish readers was higher than that of the English readers. 


\section{ACKNOWLEDGEMENTS}

My sincere appreciation is expressed to the many people who made this study possible.

To the members of my Dissertation Committee, Dr. R. Ann Zinck, Chairman, Dr. David Baral, Dr. Gayle Woolley, Dr. Durlynn Anema, and Dr. Stephen Weisgerber, for their counsel, guidance, and critical analyses during the preparation and development of the study.

Special appreciation goes to Dr. R. Ann Zinck for her support, patience, time, expertise, and helpful advice throughout the months of work expended on this study. There could have been no better dissertation chairman.

To my best friend, Kathleen Betz, for all the help, support, motivation, time, and encouragement, and for knowing when I needed each. Thank you, you really helped me make it through.

Finally, to my parents, Carlos and Lidia Bonilla, for their love, support, pride and belief in me, and for their never ending encouragement. Thank you both. 
TABLE OF CONTENTS

Page

LIST OF TABLES

CHAPTER

I. BACKGROUND OF THE STUDY . . . . . . . . . . . 1

Introduction . . . . . . . . . . . 1

Purpose of the Study . . . . . . . . . 6

Statement of the Problem . . . . . . . 6

Hypotheses . . . . . . . . . . . . 8

Significance of the Study . . . . . . . 11

Definition of Terms . . . . . . . . . 12

Limitations and Assumptions . . . . . . 13

Summary • . . . . . . . . . . . 14

II. REVIEW OF RELATED LITERATURE . . . . . . . 16

Introduction . . . . . . . . . . 16

Strategy of Questioning . . . . . . . 17

Textbook Questions and Cognitive Objectives . 24

The Barrett Taxonomy . . . . . . . . 29

Readability Formulas . . . . . . . . 32

Summary . . . . . . . . . . . . 35

III. METHODS AND PROCEDURES . . . . . . . . . 37

Introduction . . . . . . . . . . 37

Selection of Reading Series and Questions

for Analysis . . . . . . . . . . 37

Readability Level . . . . . . . . . . 39 
Statistical Analysis . . . . . . . . 40

Reliability and Validity . . . . . . . 41

Summary . . . . . . . . . . . . 43

IV. ANALYSIS OF DATA • . . . . . . . . . . 45

Introduction . . . . . . . . . . . 45

Findings for the Hypotheses of the Study . . 47

Summary . . . . . . . . . . . . 90

V. SUMMARY, DISCUSSION AND CONCLUSIONS,

RECOMMENDATIONS • • • • • • • • • • • • 94

Summary . . . . . . . . . . . . 94

Summary of the Statistical Analysis . . . . 96

Discussion and Conclusions . . . . . . 104

Recommendations . . . . . . . . . 110

REFERENCES . • • . . . . . . . . . . . . . . . 114

APPENDIXES

A. The Barrett Taxonomy of Reading Comprehension 123

B. Classification of 69 Reading Questions in English . . . . . . . . . . . 129

C. Classification of 63 Reading Questions in Spanish . . . . . . . . . . 133

D. Basal Readers Selected for Study . . . . 136

E. Stories Selected for Study . . . . . . 139 
1. Chi Square Analysis of Question Types in Three Spanish Basal Series at Grade One . . . . . .

2. Chi Square Analysis of Question Types in Three Spanish Basal Series at Grade Two . . . . . .

3. Chi Square Analysis of Question Types in Three Spanish Basal Series at Grade Three . . . . .

4. Chi Square Analysis of Question Types in Three English Basal Series at Grade One . . . . . .

5. Chi Square Analysis of Question Types in Three English Basal Series at Grade Two . . . . . .

6. Chi Square Analysis of Question Types in Three English Basal Series at Grade Three . . . . .

7. Descriptive Statistics of Question Types in Three Spanish Basal Series at Grades One and Two . . .

8. Descriptive Statistics of Question Types in Three Spanish Basal Series at Grades One and Three . .

9. Descriptive Statistics of Question Types in Three Spanish Basal Series at Grades Two and Three . .

10. Descriptive Statistics of Question Types in Three English Basal Series at Grades One and Two . . .

11. Descriptive Statistics of Question Types in Three English Basal Series at Grades One and Three .

12. Descriptive Statistics of Question Types in Three English Basal Series at Grades Two and Three . .

13. Chi Square Analysis of Question Types in the Economy English and Spanish Basal Series at Grade One . . . . . . . . . . . . . . . .

14. Chi Square Analysis of Question Types in the Economy English and Spanish Basal Series at Grade Two . . . . . . . . . . . . . . . 
15. Chi Square Analysis of Question Types in the Economy English and Spanish Basal Series at Grade Three . . . . . . . . . . . . . .

16. Chi Square Analysis of Question Types in the Santillana English and Spanish Basal Series at Grade One . . . . . . . . . . . . . .

17. Chi Square Analysis of Question Types in the Santillana English and Spanish Basal Series at

Grade Two . . . . . . . . . . . . . .

18. Chi Square Analysis of Question Types in the Santillana English and Spanish Basal Series at Grade Three . . . . . . . . . . . . . . .

19. Chi Square Analysis of Question Types in the Crane English and Spanish Basal Series at Grade One .

20. Chi Square Analysis of Question Types in the Crane English and Spanish Basal Series at Grade Two .

21. Chi Square Analysis of Question Types in the Crane English and Spanish Basal Series at Grade Three.

22. Chi Square Analysis of Question Types in the Economy Grade Three Spanish and Grade Four English . . . . . . . . . . . . . .

23. Chi Square Analysis of Question Types in the Economy English Basal Series at Grade Three and Grade Four . . . . . . . . . . . . . .

24. Comparison of Readability Levels by Series in English and Spanish Basal Readers . . . . . .

25. Comparison of Readability Levels by Grade Levels in English and Spanish Basal Readers . . . . .

26. Frequency and Percentage of English Questions by Taxonomy Level . . . . . . . . . . . . . .

27. Frequency and Percentage of Spanish Questions by Taxonomy Level 


\section{LIST OF TABLES \\ (continued)}

TABLE

Page

28. Frequencies and Percentages of Reading Questions in Three Spanish Basal Series at Grades One, Two and Three. . . . . . . . . . . . . . 100

29. Frequencies and Percentages of Reading Questions in Three English Basal Series at Grades One, Two and Three... . . . . . . . . . . 101 
CHAPTER I

BACKGROUND OF THE STUDY

Introduction

For over a hundred and twenty-five years, the most common reading instruction material in classrooms has been the basal reader (Farr \& Roser, 1979). According to spache (1972), 95-98 percent of elementary schools and 80 percent of intermediate grades use basal readers as the major source of reading instruction.

Basal reading commonly means a systematic attempt to teach children by giving them daily instruction in reading. The primary concept behind the development of basal readers is that children must be taught to read in a systematic manner, via structured lessons which gradually increase in difficulty, and that the best way to present this material to children is in the form of carefully graded readers (Yoakam, 1955). In addition, basal readers employ a limited and controlled vocabulary, as well as controlling for sentence length and structure within the basal texts.

Today, basal readers continue to dominate reading instruction despite the many controversial issues surrounding them; they have been found to have elements of sexism and racism, to use unnatural language and to lack literary quality and meaning. Farr and Roser (1979) found that the 
major reason for these elements, was that basal reading programs provide the teacher with a total package of material and suggestions for instruction. Because of this widespread use of basal readers, it is essential to study these readers for the quality of their reading material, the interest they have for children, the instructional goals set forth and the adherence to current theory and methods.

Several studies (Staiger, 1958; Barnes, 1956; Austin \& Morrison, 1963; Chall, 1967; Sheldon, 1969) have found that publishers of basal readers have a strong influence in determining what teachers teach in reading classes. These studies show that basal readers and their manuals are widely used by American teachers.

In 1958, staiger surveyed the reading instructional programs in all of the then 48 states and Hawaii. He found that 69 percent of the schools surveyed used a single series of readers as basals. Twenty percent of the schools used two series of readers as co-basals; 5.7 percent used three series; and 5.1 percent used more than three series. Staiger also found that 99 percent of the responses indicated that the teaching manuals were used regularly (Staiger, 1958).

Barnes (1956) in an earlier study had reported essentially the same findings as staiger in a study of reading practices employed by New York state intermediate-grade teachers in New York state. 
The reading methods of 210 teachers in Ohio, Pennsylvania, and West Virginia were studied by Purcell (1958). Purcell found that all teachers in his study used basal readers as the sole material for reading instruction. In addition, he noted that all but four of the 210 teachers followed the teaching manual that accompanies the reader.

Austin and Morrison (1963) surveyed 795 school systems and found that 95 percent used basal readers in the primary grades and over 90 percent used them in grades four through six. The same authors concluded that "far too many teachers follow the manual. . ., seldom if ever exercising their own initiative and creativity in teaching" (p. 224).

Barton and wilder (1964) reported that 63 percent of the teachers they studied in grades one through three considered the reading series and their accompanying manuals to have an important influence on their beliefs about the teaching of reading. Chall (1967) concluded that "for all practical purposes American reading instruction is basal-series reading instruction" (p. 189).

The basal seems to be entrenched in the reading curriculum. Sheldon (1969) concluded that although suggestions of obsolescence and expressions of dissatisfaction have been leveled at basal readers, they continued to grow in number and remain the major material used in the United States and Canada. Thus, basal reading series are not only widely used 
but even more significant is the influence these materials have on how teachers view reading instruction.

In addition to studies of the general use of the basal reader, the questions in their teachers' manuals have also been investigated in several studies (Bartolome, 1968; Santos, 1968; Cooke, 1970; Higginbotham, 1970; Habecher, 1976). Santos (1968) found that evaluation questions were significantly lacking in the basal series used in Philippine public schools. Santos also found that in all the basals studied "recall" questions received the greatest attention. Bartolome (1968) found that a wide gap existed between the categories of objectives intended to be accomplished in basal-reader manuals and the categories of questions asked to help attain these objectives. Cooke (1970) found that 55 percent of the questions that he analyzed were classified as literal comprehension. Higginbotham (1970) found that basal reading series do not consistently provide content and methodology for teaching the skills of critical reading. Habecher (1976) concluded that knowledge and comprehension questions were more frequent than other kinds of questions in the four reading series that he analyzed.

Four of the above cited studies emphasize the need for improving questions in basal readers. Cooke (1970) recommended reducing the number of questions requiring literal comprehension. Higginbotham (1970) maintained that teachers should be made aware of the lack of provisions for teaching 
critical reading skills in some basal reading series. Habecher (1976) concluded that basal readers should not place such a great emphasis on "memory" and "recall" questions. Santos (1968) recommended that educators involved in the preparation or selection of basal readers should give attention to the quality and distribution of questions.

Research regarding the evaluation of questions in basal reading series is limited. Since Santos, Bartolome, Cooke, Higginbotham, and Habecher used different basal series, different reading levels, different classification systems and different time periods, their findings are not directly comparable. Therefore, there is a need for analyzing and evaluating a wide range of publications at all reading levels before drawing conclusions about basal readers in general.

The studies previously cited (Santos, 1968; Bartolome, 1968; Cooke, 1970; Higginbotham, 1970; Habecher, 1976) have all used basal readers published in English. There are no studies which examine the quality and type of comprehension questions found in Spanish basal series. Also, there are no studies which compare the comprehension questions found in Spanish basal series with those found in English basal series. Thus there is also a need to investigate questions used in the manuals of Spanish basal readers. 


\section{Purpose of the study}

The primary purpose of this study was to determine if there is a variation in number of questions within a given taxonomy level between parallel Spanish and English basal readers at primary grade levels. A secondary purpose was to determine if questions in a parallel Spanish and English series, that extended to fourth grade, facilitated the transition from the Spanish to the English reader. Specifically, the tasks to be accomplished in this study were: (1) to classify reading questions contained in California state-adopted parallel Spanish and English basal readers utilizing Barrett's Taxonomy, (2) to determine the number of questions each level of the taxonomy contained, (3) to determine if the number of questions within each level of the taxonomy differed by reading series among grade levels and between languages, and (4) to ascertain the readability level of each reader utilized in this study.

\section{Statement of the Problem}

Research suggests that different kinds of questions have different kinds of cognitive objectives and require different cognitive processes in order to be answered. Studies in the area of questioning also suggest that textbooks have emphasized "memory" and "recall" type questions. The level and frequency of questions found in spanish basal readers has yet to be investigated. 
The present study endeavored to answer the following questions:

1. When questions are classified using the Barrett Taxonomy, is there a difference in the number of questions assigned to each taxonomy level in each of the three spanish series for each grade level?

2. When questions are classified using the Barrett Taxonomy, is there a difference in the number of questions assigned to each taxonomy level in each of the three English series for each grade level?

3. When questions are classified using the Barrett Taxonomy, is there a difference in the number of questions assigned to each taxonomy level between different grade levels for each language?

4. When questions are classified using the Barrett Taxonomy, is there a difference in the number of questions assigned to each taxonomy level at each grade level when the English series is compared to its parallel Spanish series?

5. When the number of questions assigned to each taxonomy level are considered, to what degree does the Economy Company series facilitate transition from third grade Spanish and English readers to the fourth grade English readers? 
6. For each reading series used in this study, is there a difference in the readability level between the Spanish and English texts at each grade level?

\section{Hypotheses}

As a result of the aforementioned research questions, the following hypotheses were generated:

Hypothesis 1.1 There will be no significant differences in the number of questions assigned to each taxonomy level among the three Spanish series for grade one.

Hypothesis 1.2 There will be no significant differences in the number of questions assigned to each taxonomy level among the three Spanish series for grade two.

Hypothesis 1.3 There will be no significant differences in the number of questions assigned to each taxonomy level among the three Spanish series for grade three.

Hypothesis 2.1 There will be no significant differences in the number of questions assigned to each taxonomy level among the three English series for grade one.

Hypothesis 2.2 There will be no significant differences in the number of questions assigned to each taxonomy level among the three English series for grade two.

Hypothesis 2.3 There will be no significant differences in the number of questions assigned to each taxonomy level among the three English series for grade three. 
Hypothesis 3.1 There will be no differences in the number of questions assigned to each taxonomy level among Spanish readers at grades one and two.

Hypothesis 3.2 There will be no differences in the number of questions assigned to each taxonomy level among Spanish readers at grades one and three.

Hypothesis 3.3 There will be no differences in the number of questions assigned to each taxonomy level among Spanish readers at grades two and three.

Hypothesis 3.4 There will be no differences in the number of questions assigned to each taxonomy level among English readers at grades one and two.

Hypothesis 3.5 There will be no differences in the number of questions assigned to each taxonomy level among English readers at grades one and three.

Hypothesis 3.6 There will be no differences in the number of questions assigned to each taxonomy level among English readers at grades two and three.

Hypothesis 4.1 There will be no significant differences in the number of questions assigned to each taxonomy level between the Economy Company Spanish and English readers at grade one.

Hypothesis 4.2 There will be no significant differences in the number of questions assigned to each taxonomy level between the Economy Company Spanish and English readers at grade two. 
Hypothesis 4.3 There will be no significant differences in the number of questions assigned to each taxonomy level between the Economy Company Spanish and English readers at grade three.

Hypothesis 4.4 There will be no significant differences in the number of questions assigned to each taxonomy level between the Santillana Spanish and English readers at grade one.

Hypothesis 4.5 There will be no significant differences in the number of questions assigned to each taxonomy level between the Santillana Spanish and English readers at grade two.

Hypothesis 4.6 There will be no significant differences in the number of questions assigned to each taxonomy level between the Santillana Spanish and English readers at grade three.

Hypothesis 4.7 There will be no significant differences in the number of questions assigned to each taxonomy level between the Crane Spanish and English readers at grade one.

Hypothesis 4.8 There will be no significant differences in the number of questions assigned to each taxonomy level between the Crane Spanish and English readers at grade two.

Hypothesis 4.9 There will be no significant differences in the number of questions assigned to each taxonomy 
level between the Crane Spanish and English readers at grade three.

Hypothesis 5.1 There will be no significant differences in the number of questions assigned to each taxonomy level between the Economy Company Spanish reader at grade three and the English reader at grade four.

Hypothesis 5.2 There will be no significant differences in the number of questions assigned to each taxonomy level between the Economy Company English reader at grade three and grade four.

\section{Significance of the study}

In this study, questions contained in Spanish and English basal readers were analyzed in terms of the cognitive process each was intended to tap. If suggestions can be made to improve questioning, hopefully, the ability of pupils to think and their ability to think about what they read, will be improved. Results should be of interest and of benefit not only to researchers, but also to publishers, authors, and classroom teachers.

The results of this study may help school personnel and publishers to make more informed decisions in the development, selection and use of spanish reading programs. 


\section{Definition of Terms}

Basal Reader. A coordinated series of textbooks, workbooks, and manuals written in increasing difficulty of vocabulary and skill development (Langan, 1980).

Readability Level. The indication of the difficulty of reading material in terms of the grade level at which it might be expected to be read easily (Langan, 1980).

Readability Formula. A method of estimating the reading level of difficulty of printed material by analyzing samples taken from the selection or book (Langan, 1980).

Reading. The process of constructing meaning from written text, whereby information from the text and the knowledge possessed by the reader act together to produce meaning (Hiebert, Scott, \& Wilkinson, 1986).

Reading Level. An indication of an individual's skill development at a given time generally expressed in years and months and based on some form of formal or informal assessment (Langan, 1980).

Questions. Units of printed communication which have an interrogative intent and require a pupil response (Cooke, $1970)$

Comprehension Questions. Questions which can be classified according to a taxonomy (Cooke, 1970).

Literal Level. Literal comprehension requires the recognition or recall of ideas, information, and happenings that are explicitly stated in the materials read (Barrett, 1972). 
Inference Level. Inferential comprehension is using a synthesis of the literal content of a selection, personal knowledge, intuition, and imagination as a basis for conjectures or hypotheses (Barrett, 1972).

Evaluation Level. Evaluation requires students to make judgments about the content of their reading, judgments that have to do with its accuracy, acceptability, worth, desirability, completeness, suitability, timeliness, quality, truthfulness, or probability of occurrence (Barrett, 1972).

Appreciation Level. Appreciation deals with awareness of the literary techniques, form, styles, and structures employed by authors to stimulate emotional responses in their readers (Barrett, 1972).

\section{Limitations and Assumptions}

The limitations and assumptions upon which this study was based are listed below.

\section{Limitations}

The study is subject to the following limitations:

1. Only California state-adopted basal readers for grades one through three which exist in parallel English and Spanish versions were investigated in this study.

2. The questions were evaluated only with respect to the specific divisions, levels, and assumptions within the Barrett Taxonomy. 
3. No actual investigation of reading methodology was conducted.

\section{$\underline{\text { Assumptions }}$}

The study assumed the following:

1. The Barrett Taxonomy can appropriately be used with Spanish Reading material.

2. The hierarchy of the Barrett Taxonomy corresponds to increasing levels of cognitive processing.

3. The Reading Curriculum is heavily dominated by Basal Readers.

4. The lessons selected for analysis were representative of the entire content of the readers.

\section{Summary}

This first chapter served as an introduction to the study: stated the problem, stated the hypotheses, specified the significance of the study, defined the important terms used in the study, and outlined the limitations and assumptions upon which the research is based.

Four additional chapters comprise the remainder of the study. Chapter II will present some relevant studies regarding the nature of questions and their relationship to thinking. The Barrett Taxonomy will be identified as a suitable instrument for analyzing cognitive objectives of questions. Readability will also be discussed as it relates to reading 
comprehension. Selection of samples, instruments, and procedures used will be described in Chapter III. Chapter IV will report the findings of the study related to the stated hypotheses. Chapter $\mathrm{V}$ will include a discussion of the findings, conclusions, and recommendations for further research. 


\section{Introduction}

The role of questioning is crucial to the development of thinking. Questions asked and pupil responses constitute the main language of the classroom. The kind of question determines the kind of thought process necessary to answer it. (Cooke, 1970, p. 5)

If one of the goals of education is the development of higher cognitive processes, then the need to determine what types of questions are emphasized by both teachers and textbooks is important. The following areas will be investigated as they relate to questioning and the development of higher cognitive processes: (1) strategy of Questioning, (2) Textbook Questions and Cognitive Objectives, (3) The Barrett Taxonomy, and (4) Readability Formulas.

The first area, Strategy of Questioning, will deal with questioning that occurs in the classroom. Studies of teacher generated questions and teacher-pupil verbal interaction will be examined to determine what types of questions are emphasized by teachers. The second area, Textbook Questions and Cognitive Objectives, will be devoted to studies that investigate questions found in textbooks. Again, the material reviewed here will be used to analyze what types of questions are emphasized in textbooks. 
The Barrett Taxonomy of Reading Comprehension is examined in the third section. The taxonomy is presented as a classification system for teachers to develop purposes and questions for guiding children's reading and for determining what types of comprehension questions are emphasized in basal reading manuals (Clymer, 1968). The last section deals with the issue of readability formulas. This too relates to questioning, in that children must be able to read the material given to them in order to understand it and then be able to answer questions.

\section{Strategy of Questioning}

In a recent survey of research literature on the use of questions in reading, Gall made it clear that although educators generally agree that teachers should emphasize the development of higher cognitive processes, research spanning more than a half-century provides evidence that teachers' questions have emphasized recall of facts (Gall, 1970).

Stevens (1912) was probably the first to seriously study this issue. In a sample of high-school classes varying in grade level and subject area, she found that two-thirds of the teachers' questions required direct recall of textbook information. In a study done in 1940, Corey used three judges to classify all questions asked by teachers in a one-week period in a laboratory high school. The judges classified 71 percent of the questions as factual and 
29 percent as those which required a thoughtful answer (Corey \& Fahey, 1940).

Studies conducted in the last several years indicated that teachers' questioning practices are unchanged. Floyd (1960) classified the questions of a sample of forty "best" teachers in elementary classrooms. Specific facts were called for in 42 percent of the questions. The types of questions asked by fourteen teachers in self-contained, fifth grade social studies classrooms were studied by Schreiber. Schreiber (1967) found that the most prevalent type of question asked by teachers was the factual recall type. Far less frequently used questions were those that called for: (1) arranging information in sequential order, (2) defining and clarifying information, (3) drawing conclusions, (4) evaluating quality of source material, and (5) evaluating adequacy of data (p. 77).

Letton (1958) attempted to describe different levels of reading comprehension. She stated that comprehension questions "may easily be classified at different levels of difficulty" (p. 79). Letton developed a five level scheme for classifying reading questions: (1) factual, (2) reorganization, (3) inferential, (4) interpretive, and (5) evaluative. Letton summarized her position in the following, "It is through experience with and practice in answering comprehension questions at different levels of difficulty that mature and careful readers develop" (p. 80). 
Forty-four secondary social studies student teachers were observed by Davis and Tinsley (1967) for at least two thirty-minute periods. Seven cognitive categories were used: memory, translation, interpretation, application, analysis, synthesis, and evaluation. Davis and Tinsley concluded that student teachers in the study employed mainly memory questions and that cognitive process such as application, analysis, and synthesis were not stimulated by the student teachers' questions.

Guszak (1967) studied teachers and pupils in four classes at each of three grade levels, second, fourth, and sixth. Questions in each reading group were recorded for a period of three days. Questions were classified according to categories of recognition, recall, translation, conjecture, explanation, and evaluation. Literal comprehension questions accounted for 70.4 percent of all questions recorded for the study. Of this 70.4 percent, 56.9 percent was recall and 13.5 percent was recognition. Thus, it seems that students were responding in such a way that only a limited portion of their thinking abilities was activated.

Pupils and teachers from eight fourth, fifth, and sixth grade classes were the focus of Taba's studies to determine if specifically designed teaching strategies would enable pupils in experimental groups to master sophisticated forms of symbolic thought earlier than pupils in a control 
setting. The following experimental design was established to study the development of thinking:

Group E1 Experimental Group E1 was to be composed of students who had had one or more years of exposure to the Contra Costa County Social Studies curriculum, and whose teachers received special training.

Group E2 Experimental Group E2 was composed of students who were newly introduced to the Contra Costa curriculum and whose teachers would receive special training during the study.

Group E3 Experimental Group E3 was composed of students who were newly introduced to the Contra Costa curriculum and whose teachers were not trained during the study.

Group C Control Group C was to be composed of students exposed to their usual social studies curriculum and whose teachers were not involved in the training during the study. (Taba, 1966, p. 65)

Taba then postulated that teachers' actions would be one of the most important influences in pupil cognitive development. She verified this postulate--teachers get the kind of thinking they seek. Cognitive questions were classified according to the cognitive tasks which they elicited. These tasks are:

Cognitive Task 1: Concept Formation which consists of enumeration, grouping, and labeling (categorizing) and subsuming on a single basis or on a multiple basis;

Cognitive Task 2: Inferring and Generalizing which consist of identifying points, giving information, explaining, and making inferences, generalizing;

Cognitive Task 3: Application of Principles which consist of predicting, explaining and supporting predictions, and verifying the predictions by logical inferences. (pp. 39-43) 
In an earlier study concerned with the same major

hypothesis Taba had said,

If the development of autonomy in thinking is an important objective, the "seeking" functions of teaching assume greater importance than those of "giving." The role of questions becomes crucial, and the way of asking questions far the more influential single teaching act. A focus set by the teachers' questions circumscribes the mental operations which students can perform, determines which points they can explore, and which modes of thought they learn. (p. 53)

In 1965 Gallagher and Aschner developed the GallagherAschner system for classifying Thought Processes in the Context of Verbal Interaction. The system consists of four cognitive content areas by which a question may be classified. These are:

Cognitive-Memory (C-M)

C-M operations represent the simple reproduction of facts, formulas and other items of remembered content through use of such processes as recognition, rate memory, and selective recall.

Convergent Thinking (C-T)

Convergent thinking is thought operations involving the analysis and integration of given or remembered data. It leads to one expected result because of the tightly structured framework which limits it.

Evaluative Thinking (E-T)

Evaluative thinking deals with matters of value rather than matters of fact and is characterized by verbal performance by its judgmental character.

Divergent Thinking (D-T)

In a divergent thinking sequence, individuals are free to independently generate their own data within a data-poor situation, often taking a new direction or perspective. (pp. 5-8)

In a study of fifteen high school social studies classes, Bellack et al. (1966) found the language of the classroom to 
consist almost entirely of a teacher solicitation, predominantly by question, followed by a pupil response and a teacher reaction to the pupil response. Response and reaction were dependent upon the initial question.

Bellack et al. (1966) developed a system for analyzing total classroom language, or segments of discourse, focusing on the number of spoken lines devoted to a particular area and the sequence of segments of discourse. Eight cognitive content areas into which a question could be classified were identified. These eight cognitive areas are DefiningGeneral, Defining-Denotative, Defining-Connotative, Interpreting, Fact stating, Explaining, Opinioning, and Justifying (pp. 84-85).

From the previous studies reviewed, it is quite clear that teachers' questions have emphasized facts or "straight recall" from students and that this has been a common practice for decades. Researchers in this area have voiced a consistent plea for teachers to ask a wider variety of questions, especially more questions which emphasize the development of higher cognitive processes.

Simon and Boyer (1968), in emphasizing the need for the development of higher cognitive processes made, the following statements:

A teacher who asks only data recall questions is prescribing a different thought process than one who asks questions requiring pupils to process data. (p. 11) 
In other words, teachers' questions carry, as part of their content, prescriptions for how to think.

Also those teachers who solicit higher levels of thought as measured by the cognitive systems, tend to have students who produce higher level thought processes. In general, studies indicate that simple memory recall is the most common mental activity solicited by teachers. (p.18)

Without doubt, questions are one of the teacher's main tools for guiding and directing the student's thought toward one mode of thinking and to another. Bloom and his associates have shown that questions can be structured to provide progression from merely absorbing and recalling of facts to critical and creative thinking (Bloom et al., 1956). Research in this area indicates that the kind of questions asked has an important factor in determining the level of thinking required of children in responding to the material being read (Bellack et al., 1966; Taba \& Elzey, 1964).

The quality and techniques of questioning used by a teacher indicate the primary aims and purposes in teaching. If the main concern of the teacher is to have the students acquire factual knowledge, then it is logical to expect questions that would require students to recall what is read. If, on the other hand, the teacher's primary purpose is to stimulate the students to think not only in terms of absorbing and recalling information but also in organizing, analyzing, and synthesizing known facts to solve current problems creatively, then certain types of questions will be used that 
will provoke such types of thinking activities. As Langer (1951) pointed out,". . . the intellectual treatment of any datum, any experiences, any subject, is determined by the nature of our questions and only carried out in the answers" (p. 16)

Textbook Questions and Cognitive Objectives

Textbook questions as well as teachers' questions are important in the development of higher cognitive processes. If teachers' questions have emphasized facts or "straight recall," are textbook questions developing higher cognitive processes? Several studies (Davis and Hunkins, 1966; Santos, 1968; Bartolome, 1968; Higginbotham, 1970; Cooke, 1970; Habecker, 1976) have investigated questions in textbooks. Davis and Hunkins studied questions in social studies textbooks; the others used basal reading series. Davis and Hunkins (1966) analyzed questions in onethird of the chapters of three different fifth grade social studies textbooks. Bloom's Taxonomy was used to classify a random sample of questions. Using categories of knowledge, comprehension, application, analysis, synthesis, and evaluation, nearly 90 percent of the 732 questions were classified in the knowledge category. They reached the conclusion that remembering facts was the cognitive objective of the majority of the questions classified in their study. 
Davis and Hunkins also stated that

- . in these three textbooks, none of the questions studied required analytic thinking, only one, of all 732 questions required pupils to engage in synthesis, and only two questions necessitated evaluative thinking. (p. 288)

Using the Taxonomy of Educational Objectives: Cognitive Domain and Sander's "Taxonomy of Classroom Questions," Santos developed a Classification Scheme for Reading Questions (Santos, 1968). The categories in her classification scheme are recall, translation, application, analysis, synthesis, and evaluation. Santos' study was based on seven basal readers used for reading instruction in grades three through six in Philippine public schools.

Santos concluded that while all six cognitive skills in her classification scheme were elicited in all the books she analyzed, recall questions were overemphasized. Santos also pointed out that the reading questions in the Philippine basals used a limited variety of ways in "tapping" each cognitive skill (Santos, 1968, pp. 84-86).

Bartolome (1968) used Sanders' seven categories to compare questions and objectives observed in primary classroom lessons with questions and objectives listed in basalreader manuals. Bartolome concluded that the majority of questions asked by teachers involved the memory category.

Bartolome found that the authors of basal-reader manuals posed more questions involving translation, interpretation, and application than did teachers. He further concluded 
that the findings of the investigation "support the contention that despite widespread agreement regarding the need to develop higher intellectual skills among the students, the accomplishment of these goals is very insignificant" ( pp. 101-102) .

Higginbotham (1970) analyzed the content and methodology of four different reading series. Higginbotham's main purpose was to find out whether basal reading series provide content and methodology appropriate for teaching critical reacting skills, and if any differences exist among the four series. A total of 27,321 questions were classified as (1) factual recall, (2) literal comprehension, (3) interpretation, (4) analysis and evaluation, or (5) application. Factual recall, literal comprehension, and interpretation type questions were considered to elicit "noncritical" responses. Analysis and application questions were judged to elicit "critical" responses. Higginbotham found that the basal reading series "do not consistently provide content and methodology appropriate for teaching the skills of critical reading" (p. 102).

Cooke (1970) used Barrett's Taxonomy of Reading

Comprehension to analyze the reading comprehension questions in basal readers published by Allyn and Bacon, Harper and Row, and Macmillan. Of the 3,536 questions analyzed from all the material, Cooke found 55 percent were literal 
comprehension, 26 percent were inferential comprehension, 10 percent were appreciation, 6 percent were reorganization, and 3 percent were evaluation. Cooke concluded:

Assuming that teachers actually ask the high numbers of questions contained in the printed materials, eliminating some of the literal comprehension would reduce the amount of questioning to which pupils are subjected, while raising the cognitive objectives emphasized by questions to higher levels (p. 83).

Using Bloom's Taxonomy, Habecker (1976) developed

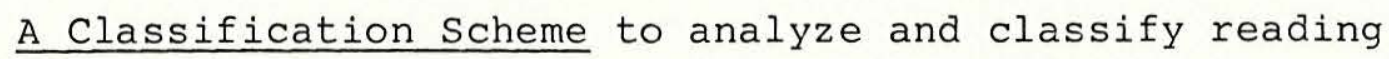
questions asked by the authors of four major publishers of basal readers during the 1950-59 period and those same publishers during the 1966-75 period. A total of 6,988 reading questions were classified. Of these 2,754 questions were from the 1950-59 period and 4,234 were from the 1966-75 period.

Habecker found that knowledge and comprehension questions were more frequent than other kinds of questions in all four series. Application questions were less frequent than other kinds of questions in all four series. Habecker concludes:

On the basis of the large percentage of knowledge questions, at all levels, and in most series, it seems clear that the basal readers have placed great emphasis on "memory" and "recall" questions in the Knowledge category ( $p$. 89).

In 1982, Arnold and Wilcox used the latest revision of the Barrett Taxonomy (Smith \& Barrett, 1974) to analyze comprehension questions in basal readers published by American 
Book Company Reading Program (1977), Ginn 720 Program (1976), and The Merrill Linguistic Reading Program (1975). The four categories of the current version of the Barrett Taxonomy were used to determine type and number of questions asked. Four stories were randomly selected from each of the fourth grade texts. Questions analyzed were those found in the teachers' manuals, the students' texts, and relevant comprehension exercises from the appropriate accompanying workbooks. A total of 623 questions were categorized. Literal and inferential questions were by far the most frequently written, making up 80 percent or more of the questions, depending on the series. Conversely, evaluation and appreciation questions were clearly deemphasized, especially evaluation questions. Inferential questions represented over one fourth of the total questions, the smallest percentage in that category for the three texts. Based on the large percentage of literal questions represented in the fourth grade texts, it was pointed out that authors of basal series perpetuated the use of literal level questions to the near exclusion of higher level questions.

Arnold and Wilcox concluded that probably the most important educational implication resulting from this study was a rather clear indication that the Barrett Taxonomy could be used to evaluate types of comprehension questions prepared to accompany texts of basal reading systems. 


\section{The Barrett Taxonomy}

In his 1967 article entitled "Goals of the Reading Program: The Basis for Evaluation," Barrett laid the foundation for a taxonomy of reading comprehension. According to Barrett (1967) reading involves perceptual, cognitive, and affective responses. This suggests that reading has three dimensions: a perceptual dimension, a meaning dimension, and an emotional dimension. Consequently, a reading program should have a strand of objectives concerned with each of these dimensions. Barrett clearly defines each of these three strands.

Perceptual goals are concerned with the flexibility, rate, and accuracy of word perception (Barrett, 1967). Although this dimension of a reading program often becomes cluttered with the listing of a variety of skills, the most fundamental goal of word perception is the use of a variety of techniques to perceive words.

Cognitive goals are concerned with the types and levels of thought generated during reading (Barrett, 1967). The overriding goal here, it seems, is to enable pupils to grow in their ability to think about and react to written material in a variety of ways. Attaining this goal has not always been possible, for at least three reasons.

First, reading comprehension has been thought of as a general ability, often interpreted to be ability to recall 
or recognize literal meaning only. Second, comprehension has been described as a fragmented ability with so many minute sub-abilities that to keep them all in mind with any continuity has been impossible. The third problem is the lack of agreement as to terminology in attempting to differentiate among such terms as creative reading, interpretive reading, and critical reading.

Barrett says the following:

In an effort to overcome these problems, it might be well to consider a classification system which would provide an understandable and manageable basis for developing specific goals, selecting learning activities, and designing evaluative techniques for the cognitive strand of the reading program.

Using some of the categories and ideas developed by Bloom (1956), Sanders (1966), Letton (1958), and Guszak (1966), it seems appropriate to suggest that the goals for the cognitive dimension of the program could be placed into four categories: (a) literal meaning, (b) inference, (c) evaluative, and (d) appreciation. (Barrett, 1967, p. 21)

Affective goals are concerned with the feelings children have toward reading, particularly the feeling that reading is worthwhile and self-fulfilling. ". . The feeling a pupil has about a specific reading selection or about reading in general will have an influence on both the perceptual and cognitive dimensions of the reading act" (Barrett, 1967, p. 23). The affective responses of pupils greatly influence what a child reads and how he reads it. Barrett, along with Krathwohl, Bloom, and Masia (1964) agree that affective goals generally deal with interests, attitudes, and values. 
Barrett's taxonomy was first published in the 1968 National Society for the Study of Education Yearbook, edited by Helen M. Robinson. The taxonomy was included in the first chapter written by Theodore Clymer. Clymer introduced the taxonomy by saying that it is manageable and understandable. Its major divisions and the comprehension tasks within them are ordered to move from the easy to the difficult. The tasks are also cumulative in that performance at any given level must utilize all previous levels. Clymer foresaw teachers using the taxonomy to develop purposes and questions for guiding children's reading and for determining what kinds of comprehension questions are emphasized in basal reading manuals (Clymer, 1968).

In the process of developing the taxonomy, Barrett drew heavily from the work of Bloom (1956), Sanders (1966), Letton (1958), and Guszak (1967). Reading comprehension, as treated in the taxonomy, is divided into four major levels: (1) Literal Comprehension, (2) Inferential Comprehension, (3) Evaluation, and (4) Appreciation (see Appendix A). Within each of the categories Barrett also provides examples of specific types of task, in the form of purposes for reading, which teachers might utilize.

The Barrett Taxonomy appears to be uniquely suited to the purpose of this research. It is designed specifically for reading comprehension. The major divisions and the levels within them claim to be hierarchically sequenced 
according to levels of cognitive difficulty and they claim to be cumulative, i.e., each thinking task implements all of the preceding thinking tasks. It is as Clymer says "manageable and understandable."

\section{Readability Formulas}

The study of readability is an area of much interest, with over a thousand publications from the 1920 s to the present. From the start, "readable" has meant "understandable," and the emphasis on this meaning has grown with the research. The effort to determine levels of readability grew out of the need to assign appropriate material to readers in various grades. There are three classes for determining readability: judgment, measures, and readability formulas (Klare, 1974). Out of the three, readability formulas will be discussed in detail.

In 1921 Thorndike developed The Teacher's Word Book and statistical techniques as a method of assessing readability (Thorndike, 1921). This new method was called a readability formula. Today there are well over 200 formulas and the number seems to be increasing.

Two types of readability formulas exist: those which rely on word list for scores which estimate semantic difficulty, and those which rely on counts of syllables for this purpose. 
In 1968 Edward Fry developed a formula which is frequently used in education (Fry, 1977). This formula is not technically a formula, but rather a graph. The main reason for the popularity of this graph is that it was reported to be "a formula that saves time" (Fry, 1968). The idea of saving time and effort is something that has been prevalent in readability research. Bormuth (1969) designed a formula for computer use with twenty variables and Jacobson (1974) developed another so complex that it can only be applied by computer. Although readability formulas were developed mostly for use with the English language, Klare points out that formulas do exist for Chinese, Dutch, Finnish, French, German, Hebrew, Russian, Spanish, Swedish, and Vietnamese languages (Klare, 1974-75).

The basis for many of the earliest formulas was the use of word frequency as an indicator of word difficulty. The first among these formulas was that of Liverly and Pressey (1923). Readability formulas then evolved into statistical regression equation forms, the first of these being the Vogel and Washburn method (1928). In an effort to minimize mismatches between readers' ability and text readability, Vogel and Washburn used a closely related reading score scale for their formula (Vogue \& Washburn, 1928). They then became the first to adopt an actual grade placement scale for their later formula. 
Many studies have been done using the Fry's Readability graph to determine reading level of readers in school. Most of the studies have been conducted using English language basal readers. In 1956, spaulding proposed a readability formula for Spanish based on the Dale-Chall formula (1948). Two elements were used for assessing readability; one was word usage and the other was sentence complexity. This formula then provided ratings whereby materials could be placed in categories but not grade levels (Spaulding, 1956). The spaulding formula was still very time-consuming.

In 1980, Gilliam, Pena, and Mountain conducted a study using the Fry's Readability Graph to determine the readability of spanish textbooks and juvenile books (Gilliam et al., 1980). They found that by modifying the Fry's Readability Graph for Spanish, they would have an instrument much simpler to use than spaulding's. Because the syllable count of a 100 word passage in spanish is much higher than that of English, Gilliam et al. (1980) found that an adjustment of "minus 67" would have to be used. This was an interesting study because it provided a simple instrument to use in determining the readability level of Spanish readers. In 1984, Crawford developed another procedure to assess the readability of elementary level material in spanish, that would be valid and reliable, yet easy to use. Crawford's study led to the development of a Fry-type formula and graph which provides a procedure as convenient to use in Spanish 
as is the Fry readability graph in English (Crawford, 1984). This section has looked at the issue of readability formulas. Many different types of formulas were presented; several formulas for use with spanish reading material were also discussed. At the beginning it was stated that "readable" means "understandable," in other words, if students are to comprehend or understand what they read they need to be able to read the material given to them. This becomes even more important when one considers that these students will be asked to answer questions, based on what they have read. For clarification, the use of readability formulas within this study were solely for purposes of verifying the level of the basal readers as described by the publishers. It was not the purpose or intention of this study to use the readability formulas to suggest controversial relationships between readability levels and the students' reading abilities.

\section{Summary}

This chapter has focused on a review of the literature pertaining to the current study in four areas: (1) strategy of questioning, (2) textbook questions and cognitive objectives (3) the Barrett Taxonomy, and (4) readability formulas.

The studies reviewed in this chapter investigating the effects of questions on pupil behavior showed that the kind 
of questions asked determine the type of response given. There seems to be a tendency among both teachers and basal readers, to emphasize questions which require literalcomprehension more than critical interpretation, and if evaluation questions are at all asked, they are answerable by "yes" or "no" and do not require the reader to weigh available evidence or to justify his responses. These findings imply the need to encourage more frequent use of questions which elicit higher-level thought processes at all grade levels.

The studies reviewed also showed that while thoughtprovoking questions offer significant contribution in the development of higher-level cognitive processes, little is done in the classroom (especially at the elementary level) to reduce the use of so-called "memory" questions. The implications of these studies indicate the need to reexamine and improve the quality and level of questioning being used. 
CHAPTER III

\section{METHODS AND PROCEDURES}

\section{Introduction}

The purposes of this study were: (1) to classify reading comprehension questions contained in California state-adopted parallel Spanish and English basal readers utilizing Barrett's Taxonomy, (2) to determine the number of questions each level of the taxonomy contained, (3) to determine if the number of questions within each level of the taxonomy differed by reading series among grade level and between languages, and (4) to ascertain the readability level of each reader utilized in this study. The procedure for selection and analysis of questions is discussed in the first section of this study. This discussion is followed by a description of the readability levels of the readers used, and the statistical analysis for the data gathered. Finally, there is a description of the study used to establish reliability of the classification process.

\section{Selection of Reading Series and Questions for Analysis}

A major criteria in the purpose of this study was to examine questions in California state-adopted Spanish and English basal readers that were parallel, i.e. both spanish and English versions from the same company. Three reading 
series met this criteria. Specifically, the series were: The Economy Company, Spanish Reading Keys (Amato et al., 1980 ) and Economy Reading Series (Matteoni et al. 1986); Santillana Publishing Company, Lectura En Dos Idiomas and Reading in Two Languages (Ramos et al., 1985); Crane Publishing Company, Spanish Crane Reading System and Crane Reading System: Pacer Program (Crane et al., 1981).

A total of 114 lesson plans were selected from the three basal series: fifty-four from the Spanish series and sixty from the English series. Six lesson plans were selected from the first, second, and third grade reading level in each of the basal series. In order to make this selection, the total number of lesson plans in each book were divided by six. For example, if a basal reader contains thirty-two lesson plans, every fifth one was selected. To insure consistency of selection in terms of difficulty and sequential development of the material, the first lesson plan in every book was used (Habecker, 1976). All reading comprehension questions within each lesson were analyzed by the investigator and classified according to the four major divisions of the Barrett Taxonomy (see Appendix A). Only lesson plans for stories and information articles were included in the samples. If a counted lesson plan dealt with a poem, a lesson on reading skills, or some other type of material, the next lesson plan based on a story or article was used for the sample. 
Within each lesson plan selected, all reading comprehension questions were analyzed and classified. The material dealing with word analysis skills (phonic analysis, structural analysis, and dictionary skills), oral reading, and the material in workbooks were not utilized in this study.

There is research that suggests there is transfer of reading skills from one language to another (Thonis, 1970; Saville \& Troike, 1971; Gutierrez, 1975; Engle, 1975; Gamez, 1979). In an effort to determine if the type of questions found in Spanish readers are preparing students for transition into an English reader, the questions and readability of the Economy Company fourth grade reader were also analyzed.

\section{Readability Level}

In order to assure continuity across both grade levels and publishers, a readability formula was applied to three 100 word samples for each reader. The Crawford Fry-Type Formula was used to determine the readability levels of the Spanish readers and the Fry Formula was used to determine the readability levels of the English readers. After finding the total number of sentences (rounding to the nearest tenth) and syllables for each, these numbers were then plotted on a graph, giving an approximate grade level. The results of the readability study will be presented and 
discussed in the next chapter. Data will be presented in tables by publisher and grade level for comparative analyses.

\section{Statistical Analysis}

Frequency distributions were calculated for all data related to comprehension questions. The distribution includes a breakdown, by series, grade level, and levels of questions. For Hypotheses 1.1 through 5.2 the independent variables were language, series, and grade level and the dependent variable was the level of the taxonomy to which the question was assigned. Hypotheses 1.1 through 2.3 and hypotheses 4.1 throuth 5.2 were analyzed using a Chi square procedure. Differences were considered significant when the confidence level was less than .05. A Cramer's V coefficient was used to determine the magnitude of the association among the level of questions, the type of reader, and grade level for each analysis. Hypotheses 3.1 through 3.6 were evaluated in terms of descriptive statistics. Percentages were used to determine the association among the level of questions, the type of reader, and grade level for each analysis.

The significance of the computed Chi square values will be presented and discussed in the next chapter and consideration will be given to the following major problems: 
1. To what extent is each cognitive skill tapped in each reader.

2. Which of the cognitive skills is most tapped in each reader? Least tapped?

3. Do the Spanish and English readers of the same series tap the same type of cognitive skills?

\section{Reliability and Validity}

In any study of this type there is the problem of rater subjectivity. In order to assess the reliability of the investigator's rating of frequency and level of questions an inter-rater reliability coefficient was used. The process for training and utilizing raters for evaluation of reliability was as follows:

1. Three doctoral candidates at the University of the Pacific who are bilingual in Spanish and English were given a copy of the taxonomy and samples of questions at various levels.

2. Each level of the taxonomy was discussed and sample questions were analyzed.

3. Raters were then given an answer sheet, a copy of the reading questions for the selection used, and a copy of the student's edition of the selection used.

4. Raters were asked to read the story carefully and analyze the questions for the selection. 
5. Raters were asked to decide whether or not each question constitutes a comprehension question according to the Barrett Taxonomy, and if so to place it at the highest congruent level.

6. Questions analyzed by individual raters were then discussed in order to resolve any differences in rating and to reach a consensus among raters.

After training, each rater then independently analyzed 132 questions from six different selections, sixty-nine questions from three selections in English, and sixtythree questions from three selections in Spanish. Before classifying each of the six different sets of questions, the following directions were given to the raters:

1. Study the behavioral tasks under each major level of the Barrett Taxonomy.

2. Read the story carefully.

3. Classify each question by referring to the story and to the Barrett Taxonomy.

4. Use the numbers below to indicate the correct level for each question.

$$
\begin{array}{ll}
\text { 1. } & \text { Literal } \\
\text { 2. Inferential } \\
\text { 3. } \\
\text { 4. Apaluation } \\
\text { Appreciation }
\end{array}
$$

For computation of inter-rater reliability, the investigator's rating was included in the data (see Appendix B and C). Inter-rater reliability was then computed on the basis of four raters. 
An analysis of variance (MANOVA) was performed using the SPSSX Users Guide (1986) in order to obtain an F-ratio. The F-ratio for English questions was 176.09249 and the F-ratio for Spanish questions was 205.06986 . The following formula was then used to obtain a reliability coefficient.

$$
R=1.00-\frac{M S W}{M S b} \text { or } 1-\frac{1}{\text { F-ratio }}
$$

A correlation of 1.0 would indicate a perfect agreement among the raters with reference to the frequency and level of questions. Reliability coefficients for both English and Spanish questions was then computed. The reliability coefficient for English was .994 indicating a high degree of agreement among the raters and the researcher in classifying question types. The reliability coefficient for spanish was .995 indicating, again, a high degree of agreement among the raters and the researcher in classifying question types.

\section{Summary}

The main purpose of this study was to analyze and classify reading questions found in three California stateadopted Spanish and English basal reading series. Three raters and the researcher were used to obtain independent judgment for establishing reliability of the Barrett Taxonomy. A total of 114 lesson plans were selected from the three major series. Questions were classified according 
to the four levels of the Barrett Taxonomy (see Appendix A) . Data gathered were converted into percentage frequencies to answer the major questions of this study. Statistical evidence to support these answers were provided by Chi square analysis to determine the significance of the difference in the distribution of reading questions, assuming uniform distribution of question types over grade levels, and of questions in each book over the four cognitive skills of the taxonomy. The percentage frequencies and Chi square analysis results will be presented and interpreted in the next chapter. 
CHAPTER IV

\section{ANALYSIS OF DATA}

\section{Introduction}

This chapter contains a presentation and analysis of data collected from the three state-adopted spanish and English Basal Readers published in California. The present study endeavored to answer the following research questions:

1. When questions are classified using the Barrett Taxonomy, is there a difference in the number of questions assigned to each taxonomy level in each of the three spanish series for each grade level?

2. When questions are classified using the Barrett Taxonomy, is there a difference in the number of questions assigned to each taxonomy level in each of the three English series for each grade level?

3. When questions are classified using the Barrett Taxonomy, is there a difference in the number of questions assigned to each taxonomy level between different grade levels for each language?

4. When questions are classified using the Barrett Taxonomy, is there a difference in the number of questions assigned to each taxonomy level at each grade level when the English series is compared to its parallel spanish series? 
5. When the number of questions assigned to each taxonomy level are considered, to what degree does the Economy Company series facilitate transition from third grade Spanish and English readers to the fourth grade English readers?

6. For each reading series used in this study, is there a difference in the readability level between the Spanish and English texts at each grade level?

These questions generated a series of hypotheses that will be presented and discussed in this chapter.

One of the basic assumptions underlying research dealing with strategies of teaching is that the technique of questioning used by the teacher plays an important role in determining the kinds and qualities of thinking experiences the students will have. Relating this assumption to reading, this study was designed to investigate the kinds of questions primary students meet in their reading classes. Comprehension questions found in Spanish and English readers were examined and classified according to the Barrett Taxonomy .

The Barrett Taxonomy contains four major divisions: Literal Comprehension (1.0), Inference (2.0), Evaluation (3.0), and Appreciation (4.0). The major divisions are sequenced according to difficulty of thought process. The divisions are also cumulative, i.e., the cognitive process 
required at each level also demands the thinking abilities of all previous levels.

A total of 5,797 comprehension questions were classified according to the Barrett Taxonomy. Of these, 2,762 questions were from the three Spanish Reading series and 3,035 were from the three English Reading Series.

Comprehension questions collected from all readers were classified at the appropriate level of the taxonomy. Data showing the number and percent of questions classified at each taxonomy level by reader, grade level, series, and language will be presented in this chapter. The general procedure to be followed in this chapter is as follows: (1) stating the hypothesis; (2) presenting the data pertinent to the hypothesis; and (3) interpreting the data as findings.

\section{Findings for the Hypotheses of the Study}

Hypothesis 1.1 There will be no significant differences in the number of questions assigned to each taxonomy level among the three Spanish series for grade one.

In order to test this hypothesis, a Chi square analysis was performed with grade one Spanish readers as the independent variable and level of question as the dependent variable. A Cramer's V was calculated to determine the magnitude of the association among the variables when the Chi square reached significance. The result of the analysis was a $x^{2}$ of $135.91(p<.0001)$ (Table 1). The Cramer's V 
TABLE 1

CHI SQUARE ANALYSIS OF QUESTION

TYPES IN THREE SPANISH BASAL

SERIES AT GRADE ONE

\begin{tabular}{|c|c|c|c|c|c|c|c|c|c|}
\hline \multirow[t]{2}{*}{ SERIES } & \multicolumn{2}{|c|}{ LITERAL } & \multicolumn{2}{|c|}{ INFERENCE } & \multicolumn{2}{|c|}{ EVALUATION } & \multicolumn{2}{|c|}{ APPRECIATION } & \multirow{2}{*}{$x^{2}$} \\
\hline & $\mathrm{N}$ & 8 & $\mathrm{~N}$ & 8 & $\mathrm{~N}$ & 8 & $\mathrm{~N}$ & $\%$ & \\
\hline ECONOMY & 100 & 82.6 & 12 & 9.9 & 6 & 5.0 & 3 & 2.5 & \\
\hline SANTILLANA & 225 & 69.9 & 80 & 24.8 & 14 & 4.3 & 3 & .9 & $135.91 *$ \\
\hline CRANE & 146 & 37.2 & 142 & 36.2 & 55 & 14.0 & 49 & 12.5 & \\
\hline TOTALS & 471 & 56.4 & 234 & 28.0 & 75 & 9.0 & 55 & 6.6 & \\
\hline
\end{tabular}

$* p<.0001$

Cramer's V $=.29$ 
of .29 indicated a low-moderate association between the series and the level of questions. Thus, approximately 8 percent of the variation in question level could be accounted for by the series in which the questions were found. Apparently, literal level questions appeared more frequently in all three series at grade one than any other level of question. In addition, the first grade spanish readers in the Crane Series tended to have more inferential, evaluation, and appreciation questions than did the other two. Hypothesis 1.1 was rejected.

Hypothesis 1.2 There will be no significant differences in the number of questions assigned to each taxonomy level among the three spanish series for grade two.

In order to test this hypothesis, a Chi square analysis was performed with grade two spanish readers as the independent variable and level of question as the dependent variable. A Cramer's V was calculated to determine the magnitude of the association among the variables when the Chi square reached significance. The result of the analysis was $a x^{2}$ of $90.90(p<.0001)$ (Table 2). The Cramer's V of . 21 indicated a small association between the series and the level of questions. Thus, approximately 5 percent of the variation in question level could be accounted for by the series in which the questions were found. Again, literal level questions appeared more frequently in all 
TABLE 2

CHI SQUARE ANALYSIS OF QUESTION

TYPES IN THREE SPANISH BASAL

SERIES AT GRADE TWO

\begin{tabular}{|c|c|c|c|c|c|c|c|c|c|}
\hline \multirow[t]{2}{*}{ SERIES } & \multicolumn{2}{|c|}{ LITERAL } & \multicolumn{2}{|c|}{ INFERENCE } & \multicolumn{2}{|c|}{ EVALUATION } & \multicolumn{2}{|c|}{ APPRECIATION } & \multirow{2}{*}{$x^{2}$} \\
\hline & $\mathrm{N}$ & 8 & $\mathrm{~N}$ & 웅 & $\mathrm{N}$ & 8 & $\mathrm{~N}$ & $\%$ & \\
\hline ECONOMY & 150 & 79.8 & 26 & 13.8 & 9 & 4.8 & 3 & 1.6 & \\
\hline SANTILLANA & 466 & 71.3 & 144 & 22.0 & 30 & 4.6 & 14 & 2.1 & $90.90 *$ \\
\hline CRANE & 76 & 50.7 & 27 & 18.0 & 32 & 21.3 & 15 & 10.0 & \\
\hline TOTALS & 692 & 69.8 & 197 & 19.9 & 71 & 7.2 & 32 & 3.2 & \\
\hline
\end{tabular}

$* p<.0001$

Cramer's V $=.21$ 
three series at grade two than any other level of question. In addition, the second grade spanish reader in the Santillana Series tended to have more literal and inferential questions than did the other two. Hypothesis 1.2 was rejected.

Hypothesis 1.3 There will be no significant differences in the number of questions assigned to each taxonomy level among the three Spanish series for grade three.

In order to test this hypothesis, a Chi square analysis was performed with grade three Spanish readers as the independent variable and level of question as the dependent variable. A Cramer's V was calculated to determine the magnitude of the association among the variables when the Chi square reached significance. The result of the analysis was a $x^{2}$ of $93.99(\mathrm{p}<.0001)$ (Table 3$)$. The Cramer's V of . 22 indicated a small association between the series and the level of questions. Thus, approximately 5 percent of the variation in question level could be accounted for by the series in which the questions were found. Apparently, literal level questions appeared more frequently in all three series at grade three than any other level of question. In addition, the third grade spanish reader in the Santillana Series tended to have more literal questions than did the other two, about three times as many. Also, the third grade spanish reader in the crane series tended to 
TABLE 3

CHI SQUARE ANALYSIS OF QUESTION

TYPES IN THREE SPANISH BASAL

SERIES AT GRADE THREE

\begin{tabular}{|c|c|c|c|c|c|c|c|c|c|}
\hline \multirow[t]{2}{*}{ SERIES } & \multicolumn{2}{|c|}{ LITERAL } & \multicolumn{2}{|c|}{ INFERENCE } & \multicolumn{2}{|c|}{ EVALUATION } & \multicolumn{2}{|c|}{ APPRECIATION } & \multirow{2}{*}{$x^{2}$} \\
\hline & $\mathrm{N}$ & 8 & $\mathrm{~N}$ & $\%$ & $\mathrm{~N}$ & 8 & $\mathrm{~N}$ & $\%$ & \\
\hline ECONOMY & 101 & 81.5 & 13 & 10.5 & 8 & 6.5 & 2 & 1.6 & \\
\hline SANTILLANA & 358 & 71.2 & 91 & 18.1 & 37 & 7.4 & 17 & 3.4 & $93.99 *$ \\
\hline CRANE & 137 & 44.5 & 74 & 24.0 & 59 & 19.2 & 38 & 12.3 & \\
\hline TOTALS & 596 & 63.7 & 178 & 19.0 & 104 & 11.1 & 57 & 6.1 & \\
\hline
\end{tabular}

$* p<.0001$

Cramer's V $=.22$ 
have more evaluation and appreciation questions than did the other two. Hypothesis 1.3 was rejected.

Hypothesis 2.1 There will be no significant differences in the number of questions assigned to each taxonomy level among the three English series for grade one.

In order to test this hypothesis, a Chi square analysis was performed with grade one English readers as the independent variable and level of question as the dependent variable. A Cramer's V was calculated to determine the magnitude of the association among the variables when the Chi square reached significance. The result of the analysis was $a x^{2}$ of $133.75(p<.0001)$ (Table 4). The Cramer's V of .31 indicated a moderate association between the series and the level of questions. Thus, approximately 10 percent of the variation in question level could be accounted for by the series in which the questions were found. As with the Spanish series, literal questions appeared more frequently in all three series at grade one than any other level of question. Furthermore, the first grade English reader in the Crane series tended to have a greater percentage of evaluation (24.7\%) and appreciation (16.0\%) questions than did the other two. Hypothesis 2.1 was rejected.

Hypothesis 2.2 There will be no significant differences in the number of questions assigned to each taxonomy level among the three English series for grade two. 
TABLE 4

CHI SQUARE ANALYSIS OF QUESTION

TYPES IN THREE ENGLISH BASAL

SERIES AT GRADE ONE

\begin{tabular}{lcccccccc}
\hline \multicolumn{1}{c}{ SERIES } & \multicolumn{2}{c}{ LITERAL } & \multicolumn{2}{c}{ INFERENCE } & EVALUATION & APPRECIATION & X \\
& $\mathrm{N}$ & 8 & $\mathrm{~N}$ & 8 & $\mathrm{~N}$ & 8 & $\mathrm{~N}$ & $\%$ \\
\hline ECONOMY & 104 & 53.9 & 76 & 39.4 & 9 & 4.7 & 4 & 2.1 \\
SANTILLANA & 193 & 67.5 & 71 & 24.8 & 16 & 5.6 & 6 & 2.1 \\
CRANE & 79 & 34.2 & 58 & 25.1 & 57 & 24.7 & 37 & 16.0 \\
\hline TOTALS & 376 & 53.0 & 205 & 28.9 & 82 & 11.5 & 47 & 6.6 \\
\hline
\end{tabular}

$* \mathrm{p}<.0001$

Cramer's V $=.31$ 
In order to test this hypothesis, a Chi square analysis was performed with grade two English readers as the independent variable and level of question as the dependent variable. A Cramer's V was calculated to determine the magnitude of the association among the variables when the Chi square reached significance. The result of the analysis was $a x^{2}$ of $144.77(p<.0001)$ (Table 5). The Cramer's V of .29 indicated a low-moderate association between the series and the level of questions. Thus, approximately 8 percent of the variation in question level could be accounted for by the series in which the questions were found. Apparently, literal level questions appeared more frequently in all three series at grade two than any other level of question. Furthermore, the second grade English reader in the Crane Series tended to have more evaluation questions, 64 as compared to 21 for the Economy Series and 32 for the Santillana Series and more appreciation questions, 60 as compared to 3 for the Economy Series and 5 for the Santillana Series. Hypothesis 2.2 was rejected.

Hypothesis 2.3 There will be no significant differences in the number of questions assigned to each taxonomy level among the three English series for grade three.

In order to test this hypothesis, a Chi square analysis was performed with grade three English readers as the independent variable and level of question as the dependent 
TABLE 5

CHI SQUARE ANALYSIS OF QUESTION

TYPES IN THREE ENGLISH BASAL

SERIES AT GRADE TWO

\begin{tabular}{|c|c|c|c|c|c|c|c|c|c|}
\hline \multirow[t]{2}{*}{ SERIES } & \multicolumn{2}{|c|}{ LITERAL } & \multicolumn{2}{|c|}{ INFERENCE } & \multicolumn{2}{|c|}{ EVALUATION } & \multicolumn{2}{|c|}{ APPRECIATION } & \multirow{2}{*}{$x^{2}$} \\
\hline & $\mathrm{N}$ & 8 & $\mathrm{~N}$ & 용 & $\mathrm{N}$ & 8 & $\mathrm{~N}$ & 8 & \\
\hline ECONOMY & 136 & 67.0 & 43 & 21.2 & 21 & 10.3 & 3 & 1.5 & \\
\hline SANTILLANA & 232 & 64.3 & 92 & 25.5 & 32 & 8.9 & 5 & 1.4 & $144.77 *$ \\
\hline CRANE & 108 & 38.2 & 51 & 18.0 & 64 & 22.6 & 60 & 21.2 & \\
\hline TOTALS & 476 & 56.2 & 186 & 22.0 & 117 & 13.8 & 68 & 8.0 & \\
\hline
\end{tabular}

$* p<.0001$

Cramer's V $=.29$ 
variable. A Cramer's $V$ was calculated to determine the magnitude of the association among the variables when the Chi square reached significance. The result of the analysis was a $x^{2}$ of $58.211(p<.0001)$ (Table 6). The Cramer's V of .15 indicated a small association between the series and the level of questions. Thus, approximately 2 percent of the variation in question level could be accounted for by the series in which the questions were found. Apparently, literal level questions appeared more frequently in all three series at grade three than any other level of question. The third grade English reader in the Santillana Series tended to have more literal questions, approximately five times as many than did the other two. But, the crane Series tended to have a greater percentage of evaluation and appreciation questions than did the other two series. Hypothesis 2.3 was rejected.

Hypothesis 3.1 There will be no differences in the number of questions assigned to each taxonomy level among Spanish readers at grade one and two.

When the number of question types among Spanish readers at grades one and two were compared it was apparent that literal level questions appeared in a larger proportion in all three series than any other level of question (Table 7). While the Santillana series had a higher number of questions at the literal level, the Economy Series had a higher percent 
TABLE 6

CHI SQUARE ANALYSIS OF QUESTION

TYPES IN THREE ENGLISH BASAL

SERIES AT GRADE THREE

\begin{tabular}{|c|c|c|c|c|c|c|c|c|c|}
\hline \multirow[t]{2}{*}{ SERIES } & \multicolumn{2}{|c|}{ LITERAL } & \multicolumn{2}{|c|}{ INFERENCE } & \multicolumn{2}{|c|}{ EVALUATION } & \multicolumn{2}{|c|}{ APPRECIATION } & \multirow{2}{*}{$x^{2}$} \\
\hline & $\mathrm{N}$ & 8 & $\mathrm{~N}$ & $\%$ & $\mathrm{~N}$ & \% & $\mathrm{N}$ & 웅 & \\
\hline ECONOMY & 119 & 52.2 & 77 & 33.8 & 28 & 12.3 & 4 & 1.8 & \\
\hline SANTILLANA & 501 & 63.0 & 181 & 22.8 & 77 & 9.7 & 36 & 4.5 & $58.211 *$ \\
\hline CRANE & 103 & 46.2 & 48 & 21.5 & 51 & 22.9 & 21 & 9.4 & \\
\hline TOTALS & 723 & 58.0 & 306 & 24.6 & 156 & 12.5 & 61 & 4.9 & \\
\hline
\end{tabular}

$* \mathrm{p}<.0001$

Cramer's V $=.15$ 
TABLE 7

\section{DESCRIPTIVE STATISTICS OF QUESTION \\ TYPES IN THREE SPANISH BASAL \\ SERIES AT GRADES \\ ONE AND TWO}

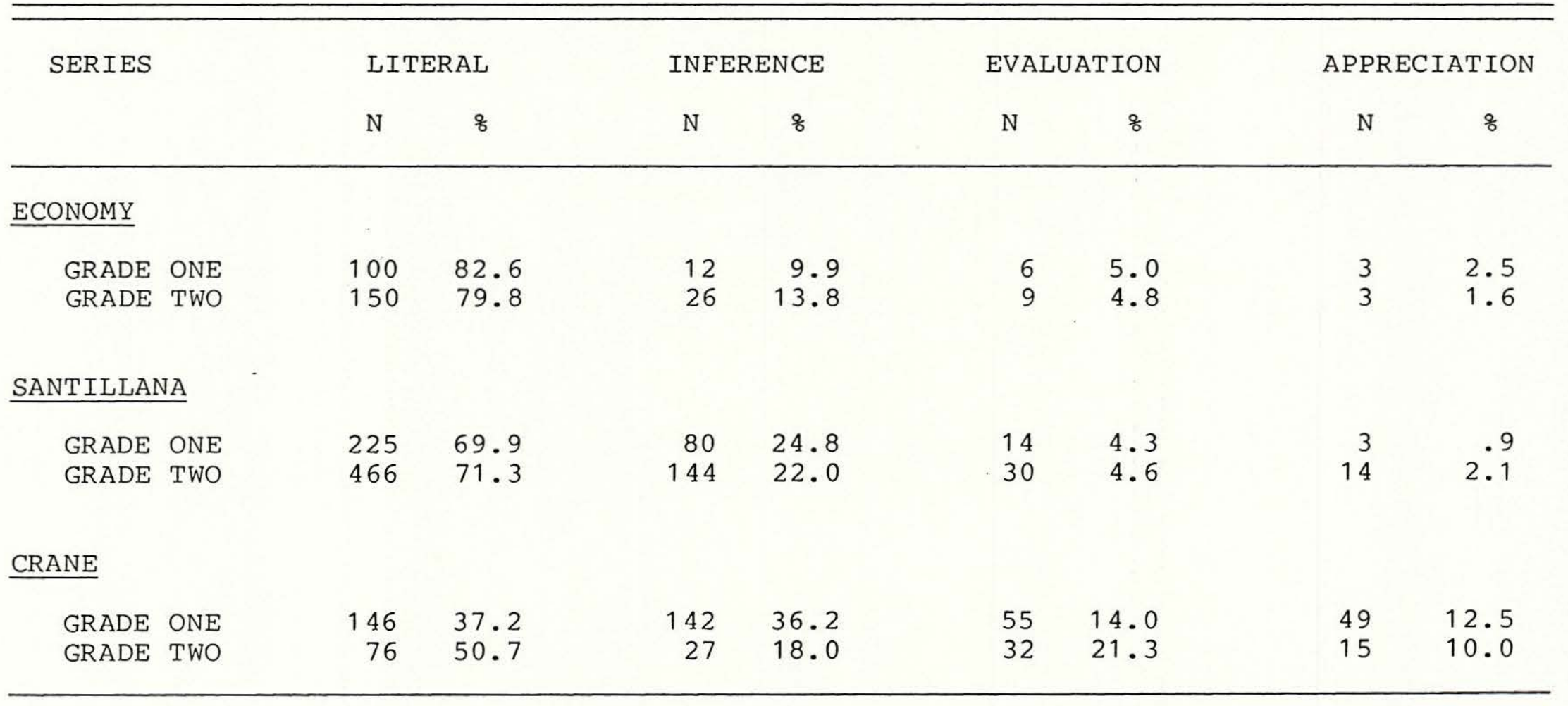


of literal questions at the first and second grade. The highest percent of inferential questions were found at grade one in the Crane Series, and at grade two in the Santillana Series. In addition, the first and second grade spanish readers in the crane Series tended to have a higher percent of both evaluation and appreciation questions than did the other two. Hypothesis 3.1 was rejected.

Hypothesis 3.2 There will be no differences in the number of questions assigned to each taxonomy level among Spanish readers at grade one and three.

When the number of question types among Spanish readers at grade one and three were compared it was apparent again, that literal level questions appeared in greater proportion in all three series than any other level of question (Table 8 ). The Santillana Series had the highest number of literal level questions at both the first and third grade. The Economy Series was found to have the highest percentage of literal level questions at grade one and grade three. The crane Series had the highest percent of inference level questions at grade one. Again, the first and third grade spanish readers in the crane series tended to have more evaluation and appreciation questions than did the other two. Hypothesis 3.2 was rejected.

Hypothesis 3.3 There will be no differences in the number of questions assigned to each taxonomy level among spanish readers at grade two and three. 
TABLE 8

DESCRIPTIVE STATISTICS OF QUESTION

TYPES IN THREE SPANISH BASAL

SERIES AT GRADES

ONE AND THREE

\begin{tabular}{|c|c|c|c|c|c|c|c|c|}
\hline \multirow[t]{2}{*}{ SERIES } & \multicolumn{2}{|c|}{ LITERAL } & \multicolumn{2}{|c|}{ INFERENCE } & \multicolumn{2}{|c|}{ EVALUATION } & \multicolumn{2}{|c|}{ APPRECIATION } \\
\hline & $\mathrm{N}$ & 8 & $\mathrm{~N}$ & 8 & $\mathrm{~N}$ & 8 & $\mathrm{~N}$ & 8 \\
\hline \multicolumn{9}{|l|}{ ECONOMY } \\
\hline $\begin{array}{ll}\text { GRADE } & \text { ONE } \\
\text { GRADE } & \text { THREE }\end{array}$ & $\begin{array}{l}100 \\
101\end{array}$ & $\begin{array}{l}82.6 \\
81.5\end{array}$ & $\begin{array}{l}12 \\
13\end{array}$ & $\begin{array}{r}9.9 \\
10.5\end{array}$ & $\begin{array}{l}6 \\
8\end{array}$ & $\begin{array}{l}5.0 \\
6.5\end{array}$ & $\begin{array}{l}3 \\
2\end{array}$ & $\begin{array}{l}2.5 \\
1.6\end{array}$ \\
\hline \multicolumn{9}{|l|}{ SANT ILLANA } \\
\hline $\begin{array}{ll}\text { GRADE } & \text { ONE } \\
\text { GRADE } & \text { THREE }\end{array}$ & $\begin{array}{l}225 \\
358\end{array}$ & $\begin{array}{l}69.9 \\
71.2\end{array}$ & $\begin{array}{l}80 \\
91\end{array}$ & $\begin{array}{l}24.8 \\
18.1\end{array}$ & $\begin{array}{l}14 \\
37\end{array}$ & $\begin{array}{l}4.3 \\
7.4\end{array}$ & $\begin{array}{r}3 \\
17\end{array}$ & $\begin{array}{r}.9 \\
3.4\end{array}$ \\
\hline \multicolumn{9}{|l|}{ CRANE } \\
\hline $\begin{array}{ll}\text { GRADE } & \text { ONE } \\
\text { GRADE } & \text { THREE }\end{array}$ & $\begin{array}{l}146 \\
137\end{array}$ & $\begin{array}{l}37.2 \\
44.5\end{array}$ & $\begin{array}{r}142 \\
74\end{array}$ & $\begin{array}{l}36.2 \\
24.0\end{array}$ & $\begin{array}{l}55 \\
59\end{array}$ & $\begin{array}{l}14.0 \\
19.2\end{array}$ & $\begin{array}{l}49 \\
38\end{array}$ & $\begin{array}{l}12.5 \\
12.3\end{array}$ \\
\hline
\end{tabular}


When the number of question types among spanish readers at grade two and three were compared it was again apparent that literal level questions appeared in a larger proportion in all three series than any other level of question (Table 9). While the Santillana series continued to have the highest number of literal questions, the highest percentages are found in the Economy Series for both grade two and three. The second and third grade Spanish readers in the crane Series continued to have more evaluation and appreciation questions than did the other two. Hypothesis 3.3 was rejected.

Hypothesis 3.4 There will be no differences in the number of questions assigned to each taxonomy level among English readers at grade one and two.

When the number of question types among English readers at grade one and two were compared it was apparent that literal level questions appeared in greater proportion in all three series than any other level of question (see Table 10). The Economy Series tended to have the highest percentage of literal questions at grade two and inferential questions at grade one. The Santillana Series appeared to have the highest percentage of literal questions at grade one, and inferential questions at grade two. In addition, the first and second grade English readers in the Crane Series tended to have more evaluation and appreciation 
TABLE 9

\section{DESCRIPTIVE STATISTICS OF QUESTION \\ TYPES IN THREE SPANISH BASAL \\ SERIES AT GRADES}

TWO AND THREE

\begin{tabular}{|c|c|c|c|c|c|c|c|c|}
\hline \multirow[t]{2}{*}{ SERIES } & \multicolumn{2}{|c|}{ LITERAL } & \multicolumn{2}{|c|}{ INFERENCE } & \multicolumn{2}{|c|}{ EVALUATION } & \multicolumn{2}{|c|}{ APPRECIATION } \\
\hline & $\mathrm{N}$ & 8 & $\mathrm{~N}$ & $\frac{8}{0}$ & $\mathrm{~N}$ & \% & $\mathrm{N}$ & 8 \\
\hline \multicolumn{9}{|l|}{$\underline{\text { ECONOMY }}$} \\
\hline GRADE TWO & 150 & 79.8 & 26 & 13.8 & 9 & 4.8 & 3 & 1.6 \\
\hline GRADE THREE & 101 & 81.5 & 13 & 10.5 & 8 & 6.5 & 2 & 1.6 \\
\hline \multicolumn{9}{|l|}{ SANTILLANA } \\
\hline GRADE TWO & 466 & $71 \cdot 3$ & 144 & 22.0 & 30 & 4.6 & 14 & 2.1 \\
\hline GRADE THREE & 358 & 71.2 & 91 & 18.1 & 37 & 7.4 & 17 & 3.4 \\
\hline \multicolumn{9}{|l|}{ CRANE } \\
\hline GRADE TWO & 76 & 50.7 & 27 & 18.0 & 32 & 21.3 & 15 & 10.0 \\
\hline GRADE THREE & 137 & 44.5 & 74 & 24.0 & 59 & 19.2 & 38 & 12.3 \\
\hline
\end{tabular}


TABLE 10

\section{DESCRIPTIVE STATISTICS OF QUESTION \\ TYPES IN THREE ENGLISH BASAL \\ SERIES AT GRADES \\ ONE AND TWO}

\begin{tabular}{|c|c|c|c|c|c|c|c|c|}
\hline \multirow[t]{2}{*}{ SERIES } & \multicolumn{2}{|c|}{ LITERAL } & \multicolumn{2}{|c|}{ INFERENCE } & \multicolumn{2}{|c|}{ EVALUATION } & \multicolumn{2}{|c|}{ APPRECIATION } \\
\hline & $\mathrm{N}$ & 8 & $\mathrm{~N}$ & 8 & $\mathrm{~N}$ & 8 & $\mathrm{~N}$ & 8 \\
\hline ECONOMY & & & & & & & & \\
\hline $\begin{array}{ll}\text { GRADE } & \text { ONE } \\
\text { GRADE } & \text { TWO }\end{array}$ & $\begin{array}{l}104 \\
136\end{array}$ & $\begin{array}{l}53.9 \\
67.0\end{array}$ & $\begin{array}{l}76 \\
43\end{array}$ & $\begin{array}{l}39.4 \\
21.2\end{array}$ & $\begin{array}{r}9 \\
21\end{array}$ & $\begin{array}{r}4.7 \\
10.3\end{array}$ & $\begin{array}{l}4 \\
3\end{array}$ & $\begin{array}{l}2.1 \\
1.5\end{array}$ \\
\hline \multicolumn{9}{|l|}{ SANT ILLANA } \\
\hline $\begin{array}{ll}\text { GRADE } & \text { ONE } \\
\text { GRADE } & \text { TWO }\end{array}$ & $\begin{array}{l}193 \\
232\end{array}$ & $\begin{array}{l}67.5 \\
64.3\end{array}$ & $\begin{array}{l}71 \\
92\end{array}$ & $\begin{array}{l}24.8 \\
25.5\end{array}$ & $\begin{array}{l}16 \\
32\end{array}$ & $\begin{array}{l}5.6 \\
8.9\end{array}$ & $\begin{array}{l}6 \\
5\end{array}$ & $\begin{array}{l}2.1 \\
1.5\end{array}$ \\
\hline CRANE & & & & & & & & \\
\hline $\begin{array}{ll}\text { GRADE } & \text { ONE } \\
\text { GRADE } & \text { TWO }\end{array}$ & $\begin{array}{r}79 \\
108\end{array}$ & $\begin{array}{l}34.2 \\
38.2\end{array}$ & $\begin{array}{l}58 \\
51\end{array}$ & $\begin{array}{l}25.1 \\
18.0\end{array}$ & $\begin{array}{l}57 \\
64\end{array}$ & $\begin{array}{l}24.7 \\
22.6\end{array}$ & $\begin{array}{l}37 \\
60\end{array}$ & $\begin{array}{l}16.0 \\
21.2\end{array}$ \\
\hline
\end{tabular}


questions than did the other two. Hypothesis 3.4 was rejected.

Hypothesis 3.5 There will be no differences in the number of questions assigned to each taxonomy level among English readers at grade one and three.

When the number of question types among English readers at grade one and three were compared it was apparent again that literal level questions appeared in greater proportion in all three series than any other level of question (Table 11). The Santillana Series appeared to have both the highest number and percent of literal questions at grade one and three. The highest percent of inferential questions for grade one and three were found in the Economy series. Furthermore, the first and third grade readers in the crane Series tended to have more evaluation and appreciation questions than did the other two series. Hypothesis 3.5 was rejected.

Hypothesis 3.6 There will be no differences in the number of questions assigned to each taxonomy level among English readers at grade two and three.

When the number of question types among English readers at grade two and three were compared it was apparent that literal level questions appeared in a larger proportion in all three series than any other level of question (Table 12). 
TABLE 11

DESCRIPTIVE STATISTICS OF QUESTION

TYPES IN THREE ENGLISH BASAL

SERIES AT GRADES

ONE AND THREE

\begin{tabular}{|c|c|c|c|c|c|c|c|c|}
\hline \multirow[t]{2}{*}{ SERIES } & \multicolumn{2}{|c|}{ LITERAL } & \multicolumn{2}{|c|}{ INFERENCE } & \multicolumn{2}{|c|}{ EVALUATION } & \multicolumn{2}{|c|}{ APPRECIATION } \\
\hline & $\mathrm{N}$ & 8 & $\mathrm{~N}$ & 8 & $\mathrm{~N}$ & 웅 & $\mathrm{N}$ & 8 \\
\hline \multicolumn{9}{|l|}{ ECONOMY } \\
\hline $\begin{array}{ll}\text { GRADE } & \text { ONE } \\
\text { GRADE } & \text { THREE }\end{array}$ & $\begin{array}{l}104 \\
119\end{array}$ & $\begin{array}{l}53.9 \\
52.2\end{array}$ & $\begin{array}{l}76 \\
77\end{array}$ & $\begin{array}{l}39.4 \\
33.8\end{array}$ & $\begin{array}{r}9 \\
28\end{array}$ & $\begin{array}{r}4.7 \\
12.3\end{array}$ & $\begin{array}{l}4 \\
4\end{array}$ & $\begin{array}{l}2.1 \\
1.8\end{array}$ \\
\hline \multicolumn{9}{|l|}{ SANT ILLANA } \\
\hline $\begin{array}{ll}\text { GRADE } & \text { ONE } \\
\text { GRADE } & \text { THREE }\end{array}$ & $\begin{array}{l}193 \\
501\end{array}$ & $\begin{array}{l}67.5 \\
63.0\end{array}$ & $\begin{array}{r}71 \\
181\end{array}$ & $\begin{array}{l}24.8 \\
22.8\end{array}$ & $\begin{array}{l}16 \\
77\end{array}$ & $\begin{array}{l}5.6 \\
9.7\end{array}$ & $\begin{array}{r}6 \\
36\end{array}$ & $\begin{array}{l}2.1 \\
4.5\end{array}$ \\
\hline \multicolumn{9}{|l|}{ CRANE } \\
\hline $\begin{array}{ll}\text { GRADE } & \text { ONE } \\
\text { GRADE } & \text { THREE }\end{array}$ & $\begin{array}{r}79 \\
103\end{array}$ & $\begin{array}{l}34.2 \\
46.2\end{array}$ & $\begin{array}{l}58 \\
48\end{array}$ & $\begin{array}{l}25.1 \\
21.5\end{array}$ & $\begin{array}{l}57 \\
51\end{array}$ & $\begin{array}{l}24.7 \\
22.9\end{array}$ & $\begin{array}{l}37 \\
21\end{array}$ & $\begin{array}{r}16.0 \\
9.4\end{array}$ \\
\hline
\end{tabular}


TABLE 12

\section{DESCRIPTIVE STATISTICS OF QUESTION \\ TYPES IN THREE ENGLISH BASAL \\ SERIES AT GRADES}

TWO AND THREE

\begin{tabular}{|c|c|c|c|c|c|c|c|c|}
\hline \multirow[t]{2}{*}{ SERIES } & \multicolumn{2}{|c|}{ LITERAL } & \multicolumn{2}{|c|}{ INFERENCE } & \multicolumn{2}{|c|}{ EVALUATION } & \multicolumn{2}{|c|}{ APPRECIATION } \\
\hline & $\mathrm{N}$ & 8 & $\mathrm{~N}$ & 옹 & $\mathrm{N}$ & 8 & $\mathrm{~N}$ & 웅 \\
\hline \multicolumn{9}{|l|}{ ECONOMY } \\
\hline $\begin{array}{ll}\text { GRADE } & \text { TWO } \\
\text { GRADE } & \text { THREE }\end{array}$ & $\begin{array}{l}136 \\
119\end{array}$ & $\begin{array}{l}67.0 \\
52.2\end{array}$ & $\begin{array}{l}43 \\
77\end{array}$ & $\begin{array}{l}21.2 \\
33.8\end{array}$ & $\begin{array}{l}21 \\
28\end{array}$ & $\begin{array}{l}10 \cdot 3 \\
12.3\end{array}$ & $\begin{array}{l}3 \\
4\end{array}$ & $\begin{array}{l}1.5 \\
1.8\end{array}$ \\
\hline \multicolumn{9}{|l|}{ SANTILLANA } \\
\hline $\begin{array}{ll}\text { GRADE } & \text { TWO } \\
\text { GRADE } & \text { THREE }\end{array}$ & $\begin{array}{l}232 \\
501\end{array}$ & $\begin{array}{l}64.3 \\
63.0\end{array}$ & $\begin{array}{r}92 \\
181\end{array}$ & $\begin{array}{l}25.5 \\
22.8\end{array}$ & $\begin{array}{l}32 \\
77\end{array}$ & $\begin{array}{l}8.9 \\
9.7\end{array}$ & $\begin{array}{r}5 \\
36\end{array}$ & $\begin{array}{l}1.5 \\
4.5\end{array}$ \\
\hline \multicolumn{9}{|l|}{ CRANE } \\
\hline $\begin{array}{ll}\text { GRADE } & \text { TWO } \\
\text { GRADE } & \text { THREE }\end{array}$ & $\begin{array}{l}108 \\
103\end{array}$ & $\begin{array}{l}38.2 \\
46.2\end{array}$ & $\begin{array}{l}51 \\
48\end{array}$ & $\begin{array}{l}18.0 \\
21.5\end{array}$ & $\begin{array}{l}64 \\
51\end{array}$ & $\begin{array}{l}22.6 \\
22.9\end{array}$ & $\begin{array}{l}60 \\
21\end{array}$ & $\begin{array}{r}21.2 \\
9.4\end{array}$ \\
\hline
\end{tabular}


The Santillana Series appeared to have the highest number and percent of literal question for both grade two and three. The percent of inferential questions were found to be high in the third grade reader in the Economy Series and in the second grade readers in the Santillana series. In addition, both the second and third grade readers English reader in the Crane Series tended to have more evaluation and appreciation questions than did the other two series. Hypothesis 3.6 was rejected.

Hypothesis 4.1 There will be no significant differences in the number of questions assigned to each taxonomy level between the Economy Company Spanish and English readers at grade one.

In order to test this hypothesis, a Chi square analysis was performed with grade one Spanish and English readers as the independent variable and level of question as the dependent variable. A Cramer's V was calculated to determine the magnitude of the association between the variables when the Chi square reached significance. The result of the analysis was a $x^{2}$ of $32.57(p<.0001)$ (Table 13). The Cramer's V of . 32 indicated a moderate association between the language and the level of questions. Thus, approximately 10 percent of the variation in question level could be accounted for by the language in which the questions were found. Apparently, literal level questions appeared more frequently in both 
TABLE 13

CHI SQUARE ANALYSIS OF QUESTION TYPES

IN THE ECONOMY ENGLISH AND SPANISH

BASAL SERIES AT GRADE ONE

\begin{tabular}{|c|c|c|c|c|c|c|c|c|c|}
\hline \multirow[t]{2}{*}{ LANGUAGE } & \multicolumn{2}{|c|}{ LITERAL } & \multicolumn{2}{|c|}{ INFERENCE } & \multicolumn{2}{|c|}{ EVALUATION } & \multicolumn{2}{|c|}{ APPRECIATION } & \multirow{2}{*}{$x^{2}$} \\
\hline & $\mathrm{N}$ & 8 & $\mathrm{~N}$ & 8 & $\mathrm{~N}$ & 8 & $\mathrm{~N}$ & $\%$ & \\
\hline \multirow[t]{2}{*}{ ENGLISH } & 104 & 53.9 & 76 & 39.4 & 9 & 4.7 & 4 & 2.1 & \\
\hline & & & & & & & & & $32.57 *$ \\
\hline SPANISH & 100 & 82.6 & 12 & 9.9 & 6 & 5.0 & 3 & 2.5 & \\
\hline TOTALS & 204 & 65.0 & 88 & 26.0 & 15 & 4.8 & 7 & 2.2 & \\
\hline
\end{tabular}

$* p<.0001$

Cramer's V $=.32$ 
languages at grade one of the Economy Series than any other level of question. In addition, the first grade English readers tended to have more inferential questions than did the Spanish. Hypothesis 4.1 was rejected.

Hypothesis 4.2 There will be no significant differences in the number of questions assigned to each taxonomy level between the Economy Company Spanish and English readers at grade two.

In order to test this hypothesis, a Chi square analysis was performed with grade two Spanish and English readers as the independent variable and level of question as the dependent variable. A Cramer's $\mathrm{V}$ was calculated to determine the magnitude of the association between the variables when the Chi square reached significance. The result of the analysis was a $x^{2}$ of $9.11(p<.05)$ (Table 14). The Cramer's $\mathrm{V}$ of .15 indicated a small association between the language and the level of questions. Thus, approximately 2 percent of the variation in question level could be accounted for by the language in which the questions were found. Apparently, literal level questions appeared more frequently in both languages at grade two of the Economy Series than any other level of question. There also, appeared to be a slightly higher number of literal questions in spanish and a slightly higher number of inferential questions in English. Hypothesis 4.2 was rejected. 


\section{TABLE 14}

CHI SQUARE ANALYSIS OF QUESTION TYPES

IN THE ECONOMY ENGLISH AND SPANISH

BASAL SERIES AT GRADE TWO

\begin{tabular}{lccccccccc}
\hline \hline LANGUAGE & \multicolumn{2}{c}{ LITERAL } & \multicolumn{2}{c}{ INFERENCE } & EVALUATION & APPRECIATION & X \\
& $\mathrm{N}$ & 8 & $\mathrm{~N}$ & 8 & $\mathrm{~N}$ & $\%$ & $\mathrm{~N}$ & $\%$ \\
\hline ENGLISH & 136 & 67.0 & 43 & 21.2 & 21 & 10.3 & 3 & 1.5 & $9.11 *$ \\
SPANISH & 150 & 79.8 & 26 & 13.8 & 9 & 4.8 & 3 & 1.6 \\
\hline TOTALS & 286 & 73.1 & 69 & 17.6 & 30 & 7.7 & 6 & 1.5 \\
\hline
\end{tabular}

$* p<.05$

Cramer's V $=.15$ 
Hypothesis 4.3 There will be no significant differences in the number of questions assigned to each taxonomy level between the Economy Company Spanish and English readers at grade three.

In order to test this hypothesis, a Chi square analysis was performed with grade three Spanish and English readers as the independent variable and level of question as the dependent variable. A Cramer's V was calculated to determine the magnitude of the association between the variables when the Chi square reached significance. The result of the analysis was $a x^{2}$ of $30.72(p<.0001)$ (Table 15). The Cramer's V of .29 indicated a small association between the language and the level of questions. Thus, approximately 8 percent of the variation in question level could be accounted for by the language in which the questions were found. Apparently literal level questions appeared more frequently in both languages at grade three of the Economy Series than any other level of question. In addition, there was a higher percentage of literal question in Spanish and a higher percentage of inferential and evaluation question in English. Hypothesis 4.3 was rejected.

Hypothesis 4.4 There will be no significant differences in the number of questions assigned to each taxonomy level between the Santillana Spanish and English readers at grade one. 
TABLE 15

CHI SQUARE ANALYSIS OF QUESTION TYPES

IN THE ECONOMY ENGLISH AND SPANISH

BASAL SERIES AT GRADE THREE

\begin{tabular}{|c|c|c|c|c|c|c|c|c|c|}
\hline \multirow[t]{2}{*}{ LANGUAGE } & \multicolumn{2}{|c|}{ LITERAL } & \multicolumn{2}{|c|}{ INFERENCE } & \multicolumn{2}{|c|}{ EVALUATION } & \multicolumn{2}{|c|}{ APPRECIATION } & \multirow{2}{*}{$x^{2}$} \\
\hline & $\mathrm{N}$ & 8 & $\mathrm{~N}$ & 웅 & $\mathrm{N}$ & 8 & $\mathrm{~N}$ & 8 & \\
\hline \multirow[t]{2}{*}{ ENGL ISH } & 119 & 52.2 & 77 & 33.8 & 28 & 12.3 & 4 & 1.8 & \\
\hline & & & & & & & & & $30.72 *$ \\
\hline SPANISH & 101 & 81.5 & 13 & 10.5 & 8 & 6.5 & 2 & 1.6 & \\
\hline TOTALS & 220 & 62.5 & 90 & 25.6 & 36 & 10.2 & 6 & 1.7 & \\
\hline
\end{tabular}

$* p<.0001$

Cramer's V $=.29$ 
In order to test this hypothesis, a chi square analysis was performed with grade one Spanish and English readers as the independent variable and level of question as the dependent variable. The result of the analysis was a $x^{2}$ of 2.0 (Table 16). Since, the Chi square did not reach statistical significance it is apparent that there is no clear association between the level of question and the language when the first grade Spanish and English readers in the Santillana Series were analyzed. Hypothesis 4.4 was accepted.

Hypothesis 4.5 There will be no significant differences in the number of questions assigned to each taxonomy level between the Santillana Spanish and English readers at grade two.

In order to test this hypothesis, a Chi square analysis was performed with grade two Spanish and English readers as the independent variable and level of question as the dependent variable. A Cramer's $\mathrm{V}$ was calculated to determine the magnitude of the association between the variables when the Chi square reached significance. The result of the analysis was $a x^{2}$ of $10.53(p<.05)$ (Table 17). The Cramer's $V$ of .10 indicated a very small association between the language and the level of questions. Thus, approximately 1 percent of the variation in question level could be accounted for by the language in which the questions were found. Apparently, literal level questions appeared more frequently in both 
TABLE 16

CHI SQUARE ANALYSIS OF QUESTION TYPES

IN THE SANTILLANA ENGLISH AND SPANISH

BASAL SERIES AT GRADE ONE

\begin{tabular}{|c|c|c|c|c|c|c|c|c|c|}
\hline \multirow[t]{2}{*}{ LANGUAGE } & \multicolumn{2}{|c|}{ LITERAL } & \multicolumn{2}{|c|}{ INFERENCE } & \multicolumn{2}{|c|}{ EVALUATION } & \multicolumn{2}{|c|}{ APPRECIATION } & \multirow{2}{*}{$x^{2}$} \\
\hline & $\mathrm{N}$ & 8 & $\mathrm{~N}$ & 웅 & $\mathrm{N}$ & 8 & $\mathrm{~N}$ & $\frac{8}{8}$ & \\
\hline \multirow[t]{2}{*}{ ENGL ISH } & 193 & 67.5 & 71 & 24.8 & 16 & 5.6 & 6 & 2.1 & \\
\hline & & & & & & & & & 2.0 \\
\hline SPANISH & 225 & 69.9 & 80 & 24.8 & 14 & 4.3 & 3 & .9 & \\
\hline TOTALS & 418 & 68.8 & 151 & 24.8 & 30 & 4.9 & 9 & 1.5 & \\
\hline
\end{tabular}




\section{TABLE 17}

CHI SQUARE ANALYSIS OF QUESTION TYPES

IN THE SANTILLANA ENGLISH AND SPANISH

BASAL SERIES AT GRADE TWO

\begin{tabular}{|c|c|c|c|c|c|c|c|c|c|}
\hline \multirow[t]{2}{*}{ LANGUAGE } & \multicolumn{2}{|c|}{ LITERAL } & \multicolumn{2}{|c|}{ INFERENCE } & \multicolumn{2}{|c|}{ EVALUATION } & \multicolumn{2}{|c|}{ APPRECIATION } & \multirow{2}{*}{$x^{2}$} \\
\hline & $\mathrm{N}$ & 웅 & $\mathrm{N}$ & 8 & $\mathrm{~N}$ & 웅 & $\mathrm{N}$ & 웅 & \\
\hline \multirow[t]{2}{*}{ ENGL ISH } & 232 & 64.3 & 92 & 25.5 & 32 & 8.9 & 5 & 1.4 & \\
\hline & & & & & & & & & $10.53 *$ \\
\hline SPANISH & 466 & 71.3 & 144 & 22.0 & 30 & 4.6 & 14 & 2.1 & \\
\hline TOTALS & 698 & 68.8 & 236 & 23.3 & 62. & 6.1 & 19 & 1.9 & \\
\hline
\end{tabular}

$* p<.05$

Cramer's V $=.10$ 
languages at grade two than any other level of question. There was a much higher percentage of literal level questions in Spanish and a higher percentage of evaluation level questions in English. Hypothesis 4.5 was rejected.

Hypothesis 4.6 There will be no significant differences in the number of questions assigned to each taxonomy level between the Santillana Spanish and English readers at grade three.

In order to test this hypothesis, a Chi square analysis was performed with grade two Spanish and English readers as the independent variable and level of question as the dependent variable. A Cramer's V was calculated to determine the magnitude of the association between the variables when the Chi square reached significance. The result of the analysis was a $\mathrm{x}^{2}$ of $9.209(\mathrm{p}<.05)$ (Table 18). The Cramer's $\mathrm{V}$ of .08 indicated a very small association between the language and the level of questions. An almost negligible variation $(.06 \%)$ in question level could be accounted for by the language in which the questions were found. Apparently, literal level questions appeared more frequently in both languages at grade three than any other level of question. Although there was more literal level questions in English the percentage was higher in spanish. In addition, the third grade English readers in the Santillana Series had a 
TABLE 18

CHI SQUARE ANALYSIS OF QUESTION TYPES

IN THE SANTILLANA ENGLISH AND SPANISH

BASAL SERIES AT GRADE THREE

\begin{tabular}{lccccccccc}
\hline \hline LANGUAGE & \multicolumn{2}{c}{ LITERAL } & \multicolumn{2}{c}{ INFERENCE } & EVALUATION & APPRECIATION & X \\
& $\mathrm{N}$ & 8 & $\mathrm{~N}$ & 8 & $\mathrm{~N}$ & 8 & $\mathrm{~N}$ & 8.5 \\
\hline ENGLISH & 501 & 63.0 & 181 & 22.8 & 77 & 9.7 & 36 & $4.209 *$ \\
SPANISH & 358 & 71.2 & 91 & 18.1 & 37 & 7.4 & 17 & 3.4 \\
\hline TOTALS & 859 & 66.2 & 272 & 21.0 & 114 & 8.8 & 53 & 4.1 \\
\hline
\end{tabular}

$* p<.05$

Cramer's V $=.08$ 
higher percentage of inferential, evaluation, and appreciation question than did the Spanish readers. Hypothesis 4.6 was rejected.

Hypothesis 4.7 There will be no significant differences in the number of questions assigned to each taxonomy level between the Crane Spanish and English readers at grade one.

In order to test this hypothesis, a Chi square analysis was performed with grade one Spanish and English readers as the independent variable and level of question as the dependent variable. A Cramer's $V$ was calculated to determine the magnitude of the association between the variables when the Chi Square reached significance. The result of the analysis was a $x^{2}$ of $16.432(p<.005)$ (Table 19). The Cramer's V of .16 indicated a small association between the language and the level of questions. Thus, approximately 2 percent of the variation in question level could be accounted for by the language in which the questions were found. Apparently, literal level questions appeared slightly more frequently in both languages at grade one than any other level of question. There appeared to be more literal and inferential questions in Spanish than in English. Also, the first grade English readers in the crane Series tended to have a higher percentage of inferential and appreciation questions than did the Spanish. Hypothesis 4.7 was rejected. 
TABLE 19

CHI SQUARE ANALYSIS OF QUESTION TYPES

IN THE CRANE ENGLISH AND SPANISH

BASAL SERIES AT GRADE ONE

\begin{tabular}{|c|c|c|c|c|c|c|c|c|c|}
\hline \multirow[t]{2}{*}{ LANGUAGE } & \multicolumn{2}{|c|}{ LITERAL } & \multicolumn{2}{|c|}{ INFERENCE } & \multicolumn{2}{|c|}{ EVALUATION } & \multicolumn{2}{|c|}{ APPRECIATION } & \multirow{2}{*}{$x^{2}$} \\
\hline & $\mathrm{N}$ & 웅 & $\mathrm{N}$ & $\frac{8}{8}$ & $\mathrm{~N}$ & 8 & $\mathrm{~N}$ & 웅 & \\
\hline \multirow[t]{2}{*}{ ENGLISH } & 79 & 34.2 & 58 & 25.1 & 57 & 24.7 & 37 & 16.0 & \\
\hline & & & & & & & & & $16.432 *$ \\
\hline SPANISH & 146 & 37.2 & 142 & 36.1 & 55 & 14.0 & 49 & 12.5 & \\
\hline TOTALS & 225 & 36.1 & 200 & 32.1 & 112 & 18.0 & 86 & 13.8 & \\
\hline
\end{tabular}

$* p<.005$

Cramer's V $=.16$ 
Hypothesis 4.8 There will be no significant differences in the number of questions assigned to each taxonomy level between the Crane Spanish and English readers at grade two.

In order to test this hypothesis, a Chi Square analysis was performed with grade two Spanish and English readers as the independent variable and level of question as the dependent variable. A Cramer's V was calculated to determine the magnitude of the association between the variables when the Chi square reached significance. The result of the analysis was $a x^{2}$ of $10.78(p<.05)$ (Table 20). The Cramer's $V$ of .16 indicated a small association between the language and the level of questions. Thus, approximately 2 percent of the variation in question level could be accounted for by the language in which the questions were found. Apparently, literal level questions appeared more frequently in both languages at grade two than any other level of question. Furthermore, while the second grade English readers appeared to have more literal level questions, the percentage was much higher in the Spanish readers than in the English. Also, the crane Series tended to have more appreciation questions in English than in Spanish. Hypothesis 4.8 was rejected.

Hypothesis 4.9 There will be no significant differences in the number of questions assigned to each 


\section{TABLE 20}

CHI SQUARE ANALYSIS OF QUESTION TYPES

IN THE CRANE ENGLISH AND SPANISH

BASAL SERIES AT GRADE TWO

\begin{tabular}{|c|c|c|c|c|c|c|c|c|c|}
\hline \multirow[t]{2}{*}{ LANGUAGE } & \multicolumn{2}{|c|}{ LITERAL } & \multicolumn{2}{|c|}{ INFERENCE } & \multicolumn{2}{|c|}{ EVALUATION } & \multicolumn{2}{|c|}{ APPRECIATION } & \multirow{2}{*}{$x^{2}$} \\
\hline & $\mathrm{N}$ & 웅 & $\mathrm{N}$ & 웅 & $\mathrm{N}$ & 8 & $\mathrm{~N}$ & 8 & \\
\hline \multirow[t]{2}{*}{ ENGL ISH } & 108 & 38.2 & 51 & 18.0 & 64 & 22.6 & 60 & 21.2 & \\
\hline & & & & & & & & & $10.78 *$ \\
\hline SPANISH & 76 & 50.5 & 27 & 18.0 & 32 & 21.3 & 15 & 10.0 & \\
\hline TOTALS & 184 & 42.5 & 78 & 18.0 & 96 & 22.2 & 75 & 17.3 & \\
\hline
\end{tabular}

$* p<.05$

Cramer's V $=.16$ 
taxonomy level between the Crane Spanish and English readers at grade three.

In order to test this hypothesis, a Chi square analysis was performed with grade three Spanish and English readers as the independent variable and level of question as the dependent variable. The result of the analysis was a $x^{2}$ of 2.30 (Table 21). Since, the chi square did not reach statistical significance it is apparent that there is no clear association between the level of question and the language when the third grade Spanish and English readers in the Crane Series were analyzed. Hypothesis 4.9 was accepted.

Hypothesis 5.1 There will be no significant differences in the number of questions assigned to each taxonomy level between the Economy Company Spanish reader at grade three and English reader at grade four.

In order to test this hypothesis, a Chi square analysis was performed with grade three Spanish and grade four English readers as the independent variable and the level of question as the dependent variable. A Cramer's V was calculated to determine the magnitude of the association among the variables when the chi square reached significance. The result of the analysis was a $x^{2}$ of 16.571 $(\mathrm{p}<.005)($ Table 22). The Cramer's V of .21 indicated a small association between the grade and language and the 
TABLE 21

CHI SQUARE ANALYSIS OF QUESTION TYPES

IN THE CRANE ENGLISH AND SPANISH

BASAL SERIES AT GRADE THREE

\begin{tabular}{|c|c|c|c|c|c|c|c|c|c|}
\hline \multirow[t]{2}{*}{ LANGUAGE } & \multicolumn{2}{|c|}{ LITERAL } & \multicolumn{2}{|c|}{ INFERENCE } & \multicolumn{2}{|c|}{ EVALUATION } & \multicolumn{2}{|c|}{ APPRECIATION } & \multirow{2}{*}{$x^{2}$} \\
\hline & $\mathrm{N}$ & 8 & $\mathrm{~N}$ & \% & $\mathrm{N}$ & 8 & $\mathrm{~N}$ & $\%$ & \\
\hline \multirow[t]{2}{*}{ ENGLISH } & 103 & 46.2 & 48 & 21.5 & 51 & 22.9 & 21 & 9.4 & \\
\hline & & & & & & & & & 2.30 \\
\hline SPANISH & 137 & 44.5 & 74 & 24.0 & 59 & 19.2 & 38 & 12.3 & \\
\hline TOTALS & 240 & 42.2 & 122 & 23.0 & 110 & 20.7 & 59 & 11.1 & \\
\hline
\end{tabular}




\section{TABLE 22}

CHI SQUARE ANALYSIS OF QUESTION TYPES

IN THE ECONOMY GRADE THREE SPANISH

AND GRADE FOUR ENGLISH

\begin{tabular}{|c|c|c|c|c|c|c|c|c|c|}
\hline \multirow[t]{2}{*}{ LANGUAGE } & \multicolumn{2}{|c|}{ LITERAL } & \multicolumn{2}{|c|}{ INFERENCE } & \multicolumn{2}{|c|}{ EVALUATION } & \multicolumn{2}{|c|}{ APPRECIATION } & \multirow{2}{*}{$x^{2}$} \\
\hline & $\mathrm{N}$ & 8 & $\mathrm{~N}$ & $\%$ & $\mathrm{~N}$ & 용 & $\mathrm{N}$ & 응 & \\
\hline \multicolumn{10}{|l|}{ SPANISH } \\
\hline GRADE THREE & 101 & 81.5 & 13 & 10.5 & 8 & 6.5 & 2 & 1.6 & \\
\hline & & & & & & & & & $16.571 *$ \\
\hline \multicolumn{10}{|l|}{ ENGL ISH } \\
\hline GRADE FOUR & 142 & 61.2 & 64 & 27.6 & 21 & 9.1 & 5 & 2.2 & \\
\hline TOTALS & 243 & 68.3 & 77 & 21.6 & 29 & 8.1 & 7 & 2.0 & \\
\hline
\end{tabular}

$* p<.005$

CRAMER'S V $=.21$ 
level of questions. Thus, approximately 4 percent of the variation in question level could be accounted for by the grade and language in which the questions were found. Apparently, literal level questions appeared more frequently in both grades than any other level of question. Furthermore, while the third grade spanish readers had a higher percentage of literal level questions, grade four English readers had a higher percentage of questions in the other three levels. Hypothesis 5.1 was rejected.

Hypothesis 5.2 There will be no significant differences in the number of questions assigned to each taxonomy level between the Economy Company English reader at grade three and grade four.

In order to test this hypothesis, a Chi square analysis was performed with grade three and grade four English readers as the independent variable and level of question as the dependent variable. The result of the analysis was a $x^{2}$ of 4.302 (Table 23). Since, the Chi square did not reach statistical significance it is apparent that there is no clear association between the level of question and grade level when the third and fourth grade English readers in the Economy Series were analyzed. Hypothesis 5.2 was accepted.

Research Question 6. For each reading series used in this study, is there a difference in the readability level between the Spanish and English Texts at each grade level? 
TABLE 23

CHI SQUARE ANALYSIS OF QUESTION TYPES

IN THE ECONOMY ENGLISH BASAL SERIES

AT GRADE THREE AND GRADE FOUR

\begin{tabular}{|c|c|c|c|c|c|c|c|c|c|}
\hline \multirow[t]{2}{*}{ GRADE } & \multicolumn{2}{|c|}{ LITERAL } & \multicolumn{2}{|c|}{ INFERENCE } & \multicolumn{2}{|c|}{ EVALUATION } & \multicolumn{2}{|c|}{ APPRECIATION } & \multirow{2}{*}{$x^{2}$} \\
\hline & $\mathrm{N}$ & 8 & $\mathrm{~N}$ & $\%$ & $\mathrm{~N}$ & 8 & $\mathrm{~N}$ & 8 & \\
\hline \multicolumn{10}{|l|}{ ENGLISH } \\
\hline GRADE THREE & 119 & 52.2 & 77 & 33.8 & 28 & 12.3 & 4 & 1.8 & \\
\hline & & & & & & & & & 4.302 \\
\hline \multicolumn{10}{|l|}{ ENGL ISH } \\
\hline GRADE FOUR & 142 & 61.2 & 64 & 27.6 & 21 & 9.1 & 5 & 2.2 & \\
\hline TOTALS & 261 & 56.7 & 141 & 30.7 & 49 & 10.7 & 9 & 2.0 & \\
\hline
\end{tabular}


As stated in chapter III a readability formula was applied to three 100 word samples for each reader. The results of this analysis are found in Table 24 and Table 25. Table 24 shows a comparison of readability levels by series, grade level, and language. The readability levels for the Economy Series in English range from a 1.0 at first grade to a 5.3 at third grade. The readability levels for the Economy Series in Spanish range from a 3.3 at first grade to a 4.0 at third grade. Except for the first grade English, the Economy Series is one to two years above grade level as far as readability.

The readability levels for the Santillana series in English range from a 1.0 at first grade to a 3.0 in third grade. The readability levels for the Santillana series in Spanish range from a 1.6 at first grade to a 4.2 at third grade. The Santillana series is slightly more consistent in their readability levels. The readability of the spanish readers at the second and third grade levels were about a year above grade level.

The readability levels for the Crane Series in English range from a 1.0 at first grade to a 3.9 at third grade. The readability levels for the crane series in spanish range from a 1.1 at first grade to a 3.3 at third grade. It is apparent that the Crane Spanish and English readers overall tend to be more at grade level than any other series. 
TABLE 24

COMPARISON OF READABILITY LEVELS

BY SERIES IN ENGLISH AND SPANISH

BASAL READERS

\begin{tabular}{|c|c|c|}
\hline SERIES & GRADE LEVEL & READABILITY \\
\hline ECONOMY - ENGLISH & $\begin{array}{l}1 \\
2 \\
3 \\
4\end{array}$ & $\begin{array}{l}1.0 \\
3.5 \\
5.3 \\
6.0\end{array}$ \\
\hline ECONOMY - SPANISH & $\begin{array}{l}1 \\
2 \\
3\end{array}$ & $\begin{array}{l}3.3 \\
4.1 \\
4.0\end{array}$ \\
\hline SANTILLANA - ENGLISH & $\begin{array}{l}1 \\
2 \\
3\end{array}$ & $\begin{array}{l}1.0 \\
2.2 \\
3.0\end{array}$ \\
\hline SANTILLANA - SPANISH & $\begin{array}{l}1 \\
2 \\
3\end{array}$ & $\begin{array}{l}1.6 \\
3.2 \\
4.2\end{array}$ \\
\hline CRANE - ENGLISH & $\begin{array}{l}1 \\
2 \\
3\end{array}$ & $\begin{array}{l}1.0 \\
2.0 \\
3.9\end{array}$ \\
\hline CRANE-SPANISH & $\begin{array}{l}1 \\
2 \\
3\end{array}$ & $\begin{array}{l}1.1 \\
2.4 \\
3.3\end{array}$ \\
\hline
\end{tabular}


Table 25 shows a comparison of readability levels by grade level, series, and language. Apparently, first grade readers in English for all three series were on grade level. The Economy series first grade reader in spanish was at least two years above grade level. When looking at the second grade readers in English, the Economy series is again above grade level (3.5). The second grade Spanish readers for both the Economy Series and the Santillana Series are above grade level (4.1 and 3.2). The third grade English reader in the Economy Series is at least two years above grade level (5.3). Spanish readers in the Economy Series and the Santillana Series at grade three are both one year above grade level.

\section{Summary}

Hypothesis 1.1 through 1.3 addressed the research question related to the number of questions assigned to each taxonomy level in the three Spanish series for each grade level. These hypotheses were rejected, based on the results of the Chi Square analysis. Hypotheses 2.1 through 2.3 addressed the research question related to the number of questions assigned to each taxonomy level in the three English series for each grade level. These hypotheses were rejected, based on the results of the chi square analysis. Thus, associations were found in the number of questions 
TABLE 25

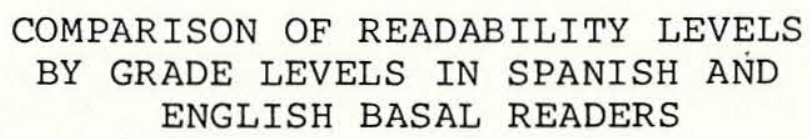

FIRST GRADE - ENGLISH

ECONOMY

SANTILLANA

CRANE

FIRST GRADE - SPANISH

ECONOMY

SANT ILLANA

CRANE

SECOND GRADE - ENGLISH ECONOMY

SANTILLANA

CRANE

SECOND GRADE - SPANISH

ECONOMY

SANTILLANA

CRANE

THIRD GRADE - ENGLISH

ECONOMY

SANTILLANA

CRANE

5.3
3.0
3.9

5.3
3.0
3.9

5.3
3.0
3.9

THIRD GRADE - SPANISH

ECONOMY

SANT ILLANA

CRANE

1.0

1.0

1.0

3.3

1. 6

1.1

3.5

2.2

2.0

4.1

3.2

2.4

4.0

4.2

3.3

FOURTH GRADE - ENGLISH ECONOMY
6.0 
within each taxonomy level across both the Spanish and English reading series at each grade level.

Hypotheses 3.1 through 3.6 addressed the research question related to the number of questions assigned to each taxonomy level between different grade levels for each language. These hypotheses were rejected, based on the evaluation of descriptive statistics. Thus, associations were found in the number of questions within each taxonomy level, series, and grade level.

Hypotheses 4.1 through 4.9 addressed the research question related to the comparison of the number of questions assigned to each taxonomy level according to language in each of the series for each grade level. Hypotheses 4.4 and 4.9 were accepted, based on the results of the Chi square analysis. At these grade levels and these series, no association between language and number of questions assigned to a taxonomy level was found. Hypotheses 4.1 through 4.3 and 4.5 through 4.8 were rejected, based on the results of Chi square analysis. Thus, an association was found in the number of questions within each taxonomy level and the language of the series.

Hypotheses 5.1 and 5.2 addressed the research question related to the degree with which the number of questions assigned to each taxonomy level facilitate transition from third grade Spanish and English readers to the fourth grade English readers. Hypothesis 5.1 was rejected, based on the 
results of the Chi Square analysis. Thus, an association was found in the number of questions within each taxonomy level across both grade levels in Spanish and English. Hypothesis 5.2 was accepted, based on the results of Chi Square analysis. Thus, no association between grade level and number of questions assigned to a taxonomy level was found. 
CHAPTER V

SUMMARY, DISCUSSION AND CONCLUSIONS, RECOMMENDATIONS

This chapter contains a summary of the study, a discussion of the findings, conclusions based on the findings, and recommendations for further research.

\section{$\underline{\text { Summary }}$}

The primary purpose of this study was to determine if there was a variation in the number of questions within a given taxonomy level between parallel Spanish and English basal readers at primary grade levels. A secondary purpose was to determine if questions in parallel spanish and English series, that extended to fourth grade, facilitated the transition from Spanish to English readering. Specifically, the tasks to be accomplished in this study were: (1) to classify reading questions contained in California state-adopted parallel Spanish and English basal readers utilizing Barrett's Taxonomy, (2) to determine the number of questions each level of the taxonomy contained, (3) to determine if the number of questions within each level of the taxonomy differed by reading series among grade levels and between languages, and (4) to ascertain the readability level of each reader utilized in this study. 
A review of the related literature established that the majority of the questions asked by teachers consist almost entirely of literal level questions. Further, evidence was presented that supported the premise that the kind of question asked determines the type of response given, and that thought-provoking questions play a significant role in the development of higher-level cognitive processes.

The Barrett Taxonomy of the Cognitive and Affective Dimensions of Reading Comprehension was used for analyzing reading comprehension questions. The major divisions and levels within the taxonomy are cumulative and thinking tasks are sequenced according to levels of difficulty.

Three California state-adopted parallel Spanish and English basal series were selected. A total of 114 lesson plans: fifty-four from the spanish series and sixty from the English series, were selected. All reading comprehension questions within each lesson were analyzed and classified according to the four major divisions of the Barrett Taxonomy. Only lesson plans for stories and information articles were included in the samples. If a lesson plan dealt with a poem, a lesson on reading skills, or some other type of material, the next lesson plan based on a story or article was used.

A total of 5,797 comprehension questions were classified according to the Barrett Taxonomy. Of these, 
2,762 questions were from the three spanish-Reading series and 3,035 were from the three English Reading Series.

Of the 3,035 comprehension questions analyzed from the three English reading series and classified in four taxonomy levels, 1,717 questions or 56.6 percent were classified as literal, 761 questions or 25.1 percent were classified as inferential, 376 questions or 12.4 percent were classified as evaluation, and 181 questions or 6.0 percent were classified as appreciation. As represented by the 56.6 percent, more than half of the questions were classified as literal (Table 26).

of the 2,762 comprehension questions analyzed from the three spanish reading series and classified in four taxonomy levels, 1,759 questions or 63.7 percent were classified as literal, 609 questions or 22.0 percent were classified as inferential, 250 questions or 9.1 percent were classified as evaluation, and 144 questions or 5.2 percent were classified as appreciation. The 63.7 percent of the questions classified as literal represent nearly two-thirds of all questions (Table 27).

\section{Summary of the Statistical Analysis}

Chi Square Analyses were used to determine if there were significant differences among the series and between grade levels in the number of questions assigned to each taxonomy level. Differences were considered significant 
TABLE 26

FREQUENCY AND PERCENTAGE OF ENGLISH

QUESTIONS BY TAXONOMY LEVEL

\section{TAXONOMY LEVEL}

FREQUENCY

PERCENTAGE

LITERAL

INFERENTIAL

EVALUATION

APPRECIATION
1,717

761

376

181
56.6

25.0

12.4

6.0

TABLE 27

FREQUENCY AND PERCENTAGE OF SPANISH

QUESTIONS BY TAXONOMY LEVEL

TAXONOMY LEVEL

FREQUENCY

PERCENTAGE

LITERAL

1,759

63.7

INFERENTIAL

609

22.0

EVALUATION

250

9.1

APPRECIATION

144

5.2

TOTAL

2,762

100.0 
when the confidence level was less than .05. A Cramer's $\mathrm{V}$ coefficient was used to determine the magnitude of the association among the level of question, type of reader, and grade level for each analysis. Descriptive statistics were used to answer research question three. Percentages were used to determine the association among the level of question, type of reader, and grade level for each analysis.

Chi square values revealed that differences do exist on the number of questions assigned to each taxonomy level among the three basal series in both languages. Chi square values also revealed that differences do exist on the number of questions assigned to each taxonomy level between the basal series when comparing parallel Spanish and English basal series at the first, second, and third grade level. Chi square values in each of these analysis were high enough to indicate that the results were not the result of chance alone.

Below are the research questions of the study and the results of the analysis for each.

Research Question 1: When questions are classified using the Barrett Taxonomy, is there a difference in the number of questions assigned to each taxonomy level in each of the three Spanish series for each grade level?

Hypotheses 1.1 through 1.3 addressed this question. These hypotheses were rejected, based on the results of the chi Square analysis. Thus, significant differences were found 
in the number of questions within each taxonomy level across the reading series at each grade level. At all grade levels, literal level questions were highest in frequency and percentage, followed by inference level questions. Evaluation level questions and appreciation level questions were in the third and fourth positions respectively. Table 28 summarizes these findings. Although the percentage of appreciation level guestions was low in all cases, the crane series tended to have more questions at this level than the other two series.

Research Question 2: When questions are classified using the Barrett Taxonomy, is there a difference in the number of questions assigned to each taxonomy level in each of the triree English series for each grade level? Hypotheses 2.1 through 2.3 adaressed this guestion. These hypotheses were rejected, based on the results of the chi Square analysis. Thus, significant differences were found in the number of questions within each taxonomy level across the reading series at each grade level. At all grade levels, literal level questions were highest in frequency and percentage, followed by inference level questions. Evaluation level questions and appreciation level questions were in third and fourth position respectively. Table 29 summarizes these findings. Although the percentage of evaluation and appreciation level questions was low in all 
TABLE 28

FREQUENCIES AND PERCENTAGES OF READING QUESTIONS IN THREE SPANISH BASAL SERIES AT GRADES

ONE, TWO AND THREE

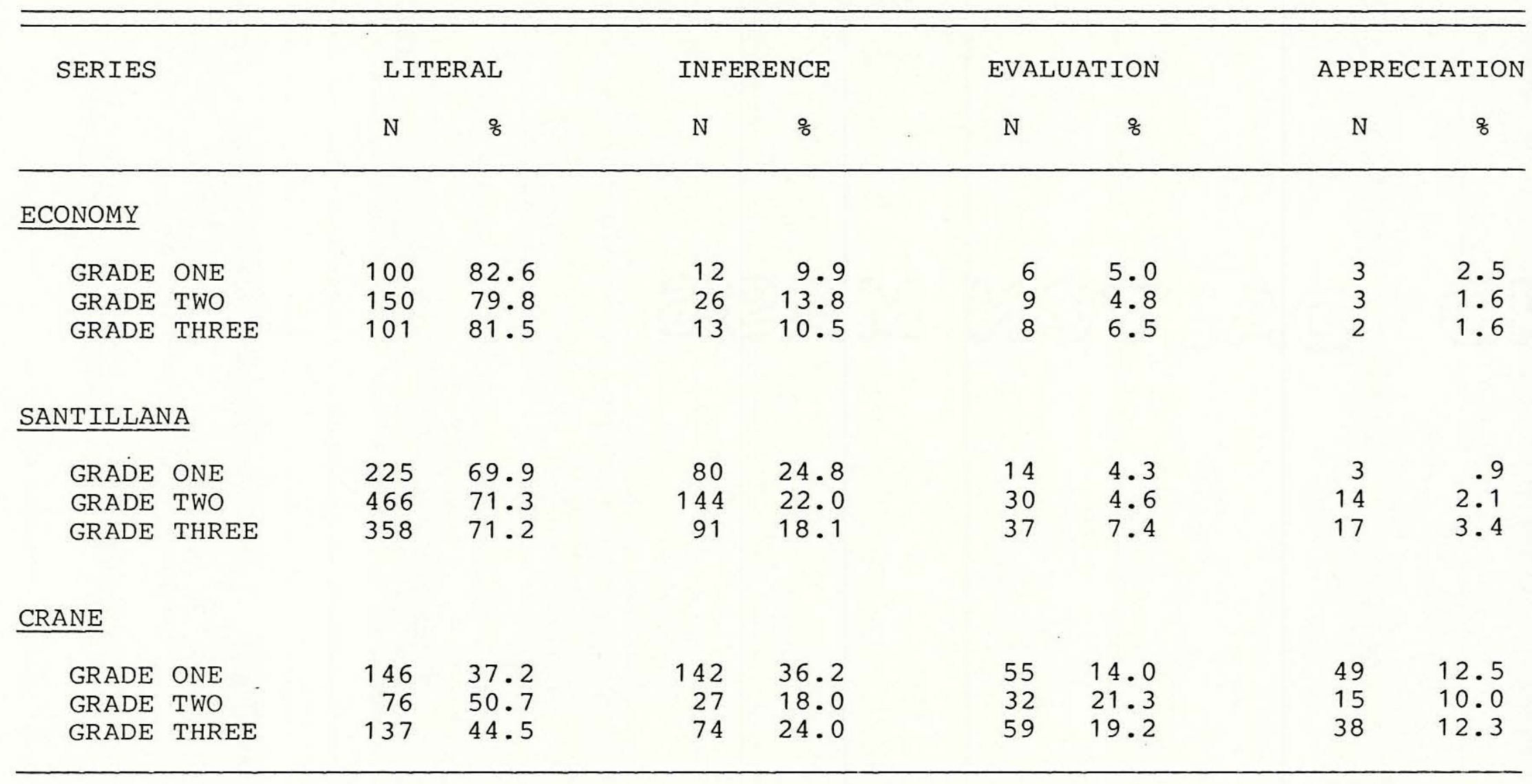


TABLE 29

FREQUENCIES AND PERCENTAGES OF READING QUFSTIONS IN

THREE ENGLISH BASAL SERIES AT GRADES

ONE, TWO AND THREE

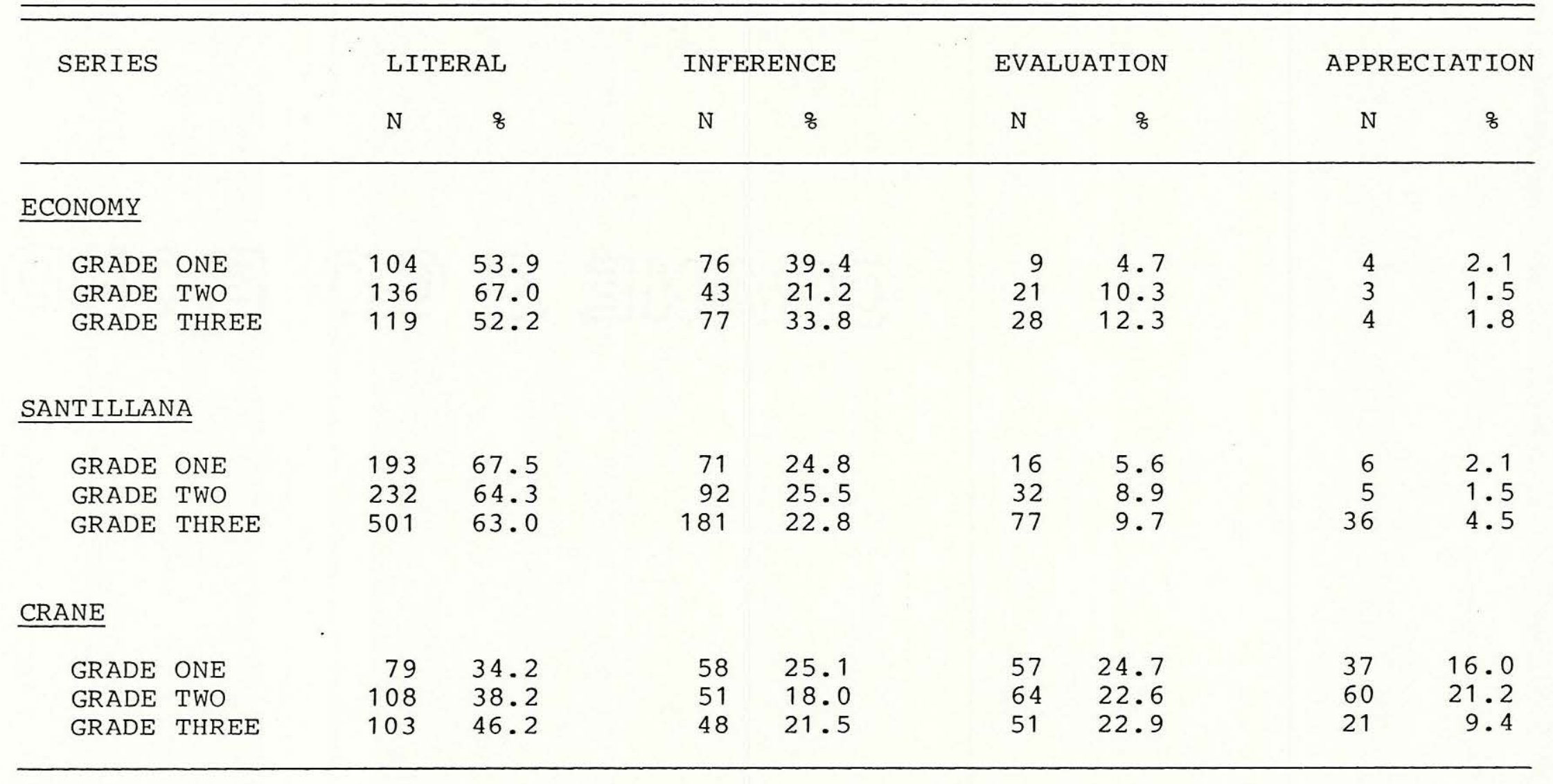


cases, the Crane series tended to have more questions at these levels than the other two series.

Research Question 3: When questions are classified using the Barrett Taxonomy, is there a difference in the number of questions assigned to each taxonomy level between different grade levels for each language? Hypotheses 3.1 through 3.6 addressed this question. These hypotheses were rejected, based on the evaluation of descriptive statistics. Thus, differences were found in the number of questions within each taxonomy level across the reading series, and between grade levels for each language. Again, literal level questions were highest in frequency and percentage, followed by inference level, evaluation level, and appreciation level questions respectively. In all cases, the Crane series tended to have more questions at the evaluation and appreciation level than the other two series. Research Question 4: When questions are classified using the Barrett Taxonomy, is there a difference in the number of questions assigned to each taxonomy level at each grade level when the English series is compared to its parallel Spanish series? Hypotheses 4.1 through 4.9 addressed this question. Hypotheses 4.4 and 4.9 were accepted based on the results of the Chi square analysis. At grade one in the Santillana series and grade three in the Crane series, no significant differences between language and the number of questions assigned to each taxonomy level 
were found. Hypotheses 4.1 through 4.3 and 4.5 through 4.8 were rejected, based on the results of the Chi square analysis. Thus, significant differences were found in the number of questions within each taxonomy level and the language of the series at each grade level. At all grade levels, literal level questions were highest in frequency and percentage, followed by inference level questions. Evaluation level questions and appreciation level questions were in the third and fourth position respectively. Although the percentage of evaluation level questions and appreciation level questions was low in all cases, the Crane series tended to have more questions at these levels than the other two series in both languages.

Research Question 5: When the number of questions assigned to each taxonomy level are considered, to what degree does the Economy Company series facilitate transition from third grade Spanish and English readers to the fourth grade English reader? Hypotheses 5.1 and 5.2 addressed this question. Hypothesis 5.1 was rejected, based on the results of Chi square analysis. Thus, differences were found in the number of questions within each taxonomy level between grade level. Literal level questions were highest in frequency and percentage, followed by inference level, evaluation level, and appreciation level questions respectively. The fourth grade English reader tended to have more questions at each level of the taxonomy than the third grade spanish 
reader. Hypothesis 5.2 was accepted, based on the results of Chi square analysis. Thus, no significant differences were found in the number of questions within each taxonomy level between grade levels when third and fourth English readers were compared.

Research Question 6: For each reading series used in this study, is there a difference in the readability level between the Spanish and English texts at each grade level? A readability formula was applied to three 100 word samples for each reader. The results of the analysis revealed that differences do exist in the readability level between the Spanish and English texts at each grade level. The first grade reader in English for all three series was on grade level. All other readers were above the stated reading level and in most cases the readability level of the spanish readers was higher than that for the English readers.

With the exception of Hypotheses $4.4,4.9$, and 5.2 where no significant associations were found, small but significant differences or associations do exist among the level of questions, the type of reader, and grade level. There seems to be a tendency among basal readers, to emphasize questions which require literal comprehension more than critical interpretation.

\section{Discussion and Conclusions}

Based on the results of this study, it is clear that the distribution of reading comprehension questions among 
the grade levels within parallel English and Spanish reading series is consistent in the heavy weighting of literal level questions. The findings of this study paralleled findings that were cited previously (Santos, 1968; Bartolome, 1968; Higginbotham, 1970; Cooke, 1970; Habecker, 1976), that is, literal level questions dominate basal readers. Since this study is the first to examine the pattern of levels of questions in spanish readers, one cannot generalize with total accuracy that all spanish readers reflect the heavy emphasis on literal questions. However, if Spanish readers are produced in America under the same sort of skills model as the English basal series, then it is very likely that the same pattern of levels of questions will exist. If the authors of these basal series planned this distribution with the emphasis on literal level questions then this is a problem. Children are not being given sufficient opportunity to develop higher order thinking skills via question response sessions (Davis \& Hunkins, 1966; Santos, 1968; Bartolome, 1968; Higginbotham, 1970; Cooke, 1970; Habecker, 1976). If this distribution is not planned and is the result of a lack of planning in the design of the comprehension questions, then the authors of the basal series are not addressing the issue of higher order thinking skills and are ignoring their responsibility to do so.

The Commission on Reading (Watson, 1987) in its recent Report Card on Basal Readers states that: 
The basal reader has evolved into an instructional technology which totally dominates reading instruction. The American basal reader is found in perhaps $90 \%$ of American classrooms, from kindergarten to sixth grade and often beyond to the eighth grade. (p. 1)

The report goes on to say that, "the basal is so dominant that it has become the reading curriculum in many schools" (p. 1). Thus basal readers continue to have a strong influence on the reading curriculum. Historically, the research overwhelmingly demonstrated that teachers utilized the questions in the basal teacher's manuals almost exclusively. In one study by Purcell (1958), only 4 out of 210 teachers did not use the manuals. The subsequent findings of Austin and Morrison (1963), Barton and Wilder (1964), and Chall (1967) also support the contention that a majority of teachers use the manuals as the major source of questions. In their report on basal readers, the Commission on Reading (1987) stated that "publishers admonish teachers not to wander from the directions of the manuals" and that administrators have supported this directive (pp. 79-80). This almost devout adherence to the manuals may have serious ramifications for the bilingual child, who needs extensive practice and application of skills beyond the literal level. Since the comprehension questions found in manuals have been found to consist primarily of literal level questions these students are not being exposed to the questions which require thinking and processing at the levels of analysis, synthesis, application, and evaluation. 
The Commission on Reading (Watson, 1987) also found that when reading comprehension questions in manuals were examined, the materials reflected the idea of comprehension as a product and not as a process. In addition, there was generally one right answer for each question.

While the use of the basal system has many implications in regard to the bilingual child, perhaps the most serious is addressed by the following: "More than anything else, the basals are built around control; they control reading; they control language . . " (Watson, 1987, p. 79). Isn't this the exact opposite of the experiences desired for these children in a basal reading situation? Through the use of the manuals, and by their very nature, we are controlling and limiting the product we wish to expand, extend, and increase. The Report Card on Basal Readers (Watson, 1987) supports this contention:

The learner needs the freedom to experiment, to take risks, to raise questions in the process of trying to make sense of comprehensible written language. Nowhere in the basals are learners encouraged to decide what is, for themselves, a good story or text. . . . This isn't just bad for their reading development. It's also bad for their development as thinkers, as learners and as participants in a democratic society. (p. 80 )

While these issues are certainly pertinent to the bilingual child, they are not pertinent to the bilingual child alone, but rather are universal goals which are desired for all learners, bilingual as well as monolingual. 
Another critical issue that could be inferred from the data is the significant difference in the pattern of question types between the Spanish third grade Economy Company readers and the English fourth grade Economy Company readers. A much greater proportion of inference, evaluation, and appreciation level questions occur in the English readers while in Spanish readers, the greater proportion is devoted to literal level. This is not the case in the English version of the third grade reader. The third grade reader does parallel the fourth grade reader in the proportion of questions within each level. Thus there is an issue of transition. Are the children in the third grade readers being prepared for the greater emphasis on higher level questions that they will encounter in the fourth grade reader? It appears that they are not. One is left to question whether this is an intentional or accidental difference. Logically, it would seem that the authors and editors in the two Economy Company series would collaborate on the development and distribution of questions in the two series. Special attention should be given to the point at which children in the spanish reader are expected to transition to the English reader. The data indicate that this is not the case.

Do the teachers ask more or fewer questions than are contained in the reading manuals, and if so is the proportion of questions still heaviest at the literal level? 
Shake and Allington (1985) found that when second grade teachers were selective about basal reading questions they often offered poor substitutes for the recommended questions after a story. Their study showed that teacher-generated questions did not differ greatly from the level of questions offered in the basals. In fact, teacher-generated questions did not lead the students beyond the literal and into the higher levels of questions any more than the manuals, indicating the need for teacher training and direction in developing quality questioning techniques.

There is virtually nothing in the literature which delineates "good" comprehension questions. One assumes that good comprehension questions are those which have higher level cognitive objectives and thus tap higher level cognitive processes. These are questions that would be classified above the literal comprehension level. When one considers that the main language of the classroom consists primarily of teacher questions and student responses, and the kind of question determines the kind of thought process necessary to answer it, then the importance of asking higher level questions is difficult to over emphasize.

The results of the present study indicate that the same pattern of question distribution exist in both English and Spanish readers. Discussion type questions which would lead to language extension and expansion would seem to be more beneficial to the bilingual and the limited English 
proficient children than the directed questions at the literal level. Involving the students in higher order thinking processes would lend opportunity for the student to engage in more involved and extended responses which might stimulate language expansion. As members of a complex society, students will be required throughout their life to engage in situations requiring thought processes and responses which delve beyond the literal stages. In order to be fully prepared to participate in society, students will need to have had a wide variety of experiences enabling them to participate in decision-making which requires analyzing, applying, and evaluating skills in addition to basic literal comprehension skills. The students' exposure to these other areas is crucial to their ability to function productively in society.

\section{Recommendations}

1. It is recommended that the basal reader publishers address the nature of the distribution of questions in their series. If it is deliberate and conscious, that is, an integral aspect of their theory and philosophy of reading instruction, then this should be stated in the manual. If it is a matter of oversight or poor question design, then it is a qualitative issue that needs to be improved.

2. It is recommended that teachers should be made aware of the disproportionate distribution of questions 
within each level in the reading series utilized in this study. Teachers could take a proactive role and demand that the publishers address this issue clearly in their manuals.

3. It is recommended that training for teachers be provided in the use of the Barrett Taxonomy as a basis for supplementing the number of higher level questions contained in the basal series and as a basis for eliminating some literal level questions.

4. It is recommended that the Barrett Taxonomy be used as one tool to facilitate the selection of basal readers. The informed use of the taxonomy would insure that an appropriate emphasis on all levels of questions exists in a given series. If one accepts the hierarchy and cumulativeness of the taxonomy, then the greater the frequency of higher level questions would contribute to enhancing the ability of the teacher in respect to the development of children's thinking. Although the issue was not addressed in this study, along with improvement of questions, a concomitant improvement in the quality of stories is recommended. During the process of analyzing questions, the researcher read all of the related stories. It was evident that the controlled vocabulary and the resulting contrived nature of the language structure contributed to stories that were, simply put, bady written. This practice is most recently documented and criticized by Kenneth Goodman (1988). 
5. It is recommended that studies be conducted utilizing Spanish and English reading series to compare growth in comprehension when one group of children is exposed to teaching with primarily literal level questions and a second group is exposed to questions emphasizing inference, evaluation, and appreciation. In addition, further studies are recommended to determine whether a systematic presentation and distribution of questions among different cognitive skills would result in the development of higher level thinking skills.

6. It is recommended that further studies involving the same variables be conducted with different series and different grade levels to determine if the results of this study are generalizable grades one through six.

7. It is recommended that basal series publishers clearly address the issue of transition from spanish to English reading series in terms of the proportion of questions devoted to each level. Since Economy Company was one publisher that provided a parallel series that extended into fourth grade, it should be a priority for them to address this issue. This finding can also stand as an indicator for the other series as well. Children will exit from Spanish readers into other English basal series in fourth grade. If the emphasis on higher level questions in fourth grade is a general trend in all series, then the Spanish reading series must address this issue in their third grade readers as well. 
REFERENCES 
Andre, Thomas. "Does Answering Higher-Level Questions While Reading Facilitate Productive Learning?" Review of Educational Research 49(2) (Spring 1979), 280-318.

Arnold, Richard D., and Wilcox, Elizabeth. "Comparing Types of Comprehension Questions Found in Fourth Grade Readers." Reading Psychology 3 (1982), 43-49.

Austin, M. C., and Morrison, C. The First R: The Harvard Report on Reading in Elementary Schools. New York: Macmillan Company, 1963.

Barnes, E. A. A Survey of Reported Practices Currently Used By Intermediate Grade Teachers in New York. (Doctoral Dissertation, Syracuse University) Ann Arbor, MI: University Microfilms, 1956. No. 56-3811.

Barrett, Thomas $\mathrm{C}$. The Evaluation of Children's Reading Achievement Perspectives in Reading, no. 8. Newark, DE: International Reading Association, 1967.

Bartolome, P. I. A Comparison of Questions and Objectives Listed in Basal Reader Guidebooks With Those Observed in the Reading Lesson. (Doctoral Dissertation, Ohio State University) Ann Arbor, Michigan: University Microfilms, 1968. No. 69-11, 606.

Barton, A. H., and Wilder, D. E. "Research and Practices in the Teaching of Reading: A Progress Report." In M. B. Miles (Ed.), Innovations in Education. New York: Bureau of Publications, Teachers College, Columbia University, 1964.

Beck, Isabel L., and McKeown, Margaret. "Developing Questions That Promote Comprehension: The Story Map." Language Arts 58, no. 8 (November/December 1981), 913-918.

Bellack, Arno A.; Kliebard, H.; Hyman, R.; and Smith, F. The Language of the Classroom. New York: T. C. Press, Teachers College, Columbia University, 1966.

Bloom, Benjamin et al. Taxonomy of Educational Objectives. New York: Longmans, Green \& Co., 1956. 
Bormuth, J. R. Development of Readability Analyses (1969), ERIC ED 029166.

Carroll, Robert P., Ph.D. An Experimental Study of Comprehension in Reading. New York: Bureau of Publications, Teachers College, Columbia University, 1926.

Chall, Jeanne S. Learning to Read: The Great Debate. New York: McGraw-Hill, 1967.

Chall, Jeanne S. Stages of Reading Development. New York: McGraw Hill, 1983.

Chase, Francis. "In the Next Decade." Controversial Issues in Reading and Promising Solutions: Proceedings of the Annual Conference on Reading. Edited by $\mathrm{H}$. M. Robinson, XXII. Chicago: University of Chicago Press, 1961 .

Ching, Doris C. Reading and the Bilingual Child. Newark, $\mathrm{DE}$ : International Reading Association, 1976.

Clewell, Suzanne, F., and Cliffton, Anne M. "Examining Your Textbook for Comprehensibility." Journal of Reading 27(3) (December 1983), 219-224.

Clymer, Theodore. "What is 'Reading'? Some Current Concepts." Innovations and Change in Reading Instruction. The Sixty-Seventh Yearbook of the National Society for the Study of Education. Edited by Helen M. Robinson. Chicago: The University of Chicago Press, 1968.

Commission on Reading. Becoming a Nation of Readers: The Report of the Commission on Reading. Washington, DC: National Institute of Education, 1985.

Cooke, Dean A. An Analysis of Reading Comprehension Questions in Basal Reading Series According to the Barrett Taxonomy. (Doctoral Dissertation, Cornell University) Ann Arbor, MI: University Microfilms, 1970. No. $71-12,124$.

Crawford, Alan N. A Spanish Language Fry-Type Readability Procedure: Elementary Level. Bilingual Education Paper Series. Los Angeles, CA: Evaluation, Dissemination and Assessment Center, 1984. 
Crisp, F. M. "Questioning Children's Reading--An Application of Barrett's Taxonomy." Reading 12(1) (April 1978), 36-43.

Dale, Edgar, and Chall, Jeanne. "A Formula for Predicting Readability." Educational Research Bulletin 27 (January 1948), 11-20.

Davis, O. L., Jr., and Hunkins, Francis, P. "Textbook Questions: What Thinking Processes Do They Foster?" Peabody Journal of Education 43 (March 1966), 285-292.

Davis, O. L., Jr., and Tinsley, Drew C. "Cognitive Objectives Revealed by Classroom Questions Asked by Social studies student Teachers." Peabody Journal of Education 45 (July 1967), 21-26.

Durkin, Dolores. "Is There a Match Between what Elementary Teachers Do and What Basal Reader Manuals Recommend?" The Reading Teacher (April 1984), 734-744.

Durkin, Dolores. "Reading Comprehension Instruction in Five Basal Series." Reading Research Quarterly 16 (1981), 515-544.

Durkin, Dolores. "What Classroom Observations Reveal About Reading Comprehension Instruction." Reading Research Quarterly $14(1978-1979), 481-533$.

Engle, Patricia L. The Use of the Vernacular Language in Education: Language Medium in Early School Years for Minority Language, Bilingual Education Series 3. Arlington, VA: The Center for Applied Linguistics, 1975.

Farr, Roger, and Roser, Nancy. Teaching a Child to Read. New York: Harcourt, Brace, Jovanovich, 1979.

Farrar, Mary T. "Asking Better Questions." The Reading Teacher (October 1984), 10-15.

Farrar, Mary T. "Another Look At Oral Questions for Comprehension." The Reading Teacher (January 1983), $370-374$.

Floyd, William. An Analysis of the Oral Questioning Activities in Selected Colorado Primary Classrooms. (Doctoral Dissertation, Colorado State College) Ann Arbor, MI: University Microfilms, 1960. No. 60-6253. 
Fry, Edward. "Fry's Readability Graph: Clarifications, Validity, and Extension to Level 17." Journal of Reading 21, no. 3 (December 1977), 242-52.

Fry, Edward. "A Readability Formula That Saves Time." Journal of Reading 11, no. 7 (April 1968), 513.

Gall, Meredith D. "The Use of Questions in Teaching." Review of Educational Research 40(5) (1970), 707-20.

Gamez, Gloria I. "Reading in a Second Language: 'Native Language Approach' vs. 'Direct Method.'" Reading Teacher $32(1979), 665-70$.

Gans, Roma. A Study of Critical Reading Comprehension in the Intermediate Grades. New York: Teachers College, Columbia University, 1940.

Gilliam, Betty; Pena, Sylvia C.; and Mountain, Lee. "The Fry Graph Applied to Spanish Readability." The Reading Teacher 33 (January 1980), 426-30.

Goodman, Kenneth. "Look What They've Done to Judy Blume!: The 'Basalization' of Children's Literature." The New Advocate 1 (1988), 29-41.

Guszak, Frank J. "Teacher Questioning and Reading." The Reading Teacher 21 (December 1967), 227-34.

Guszak, Frank J. "Teachers' Questions and Levels of Reading Comprehension." The Evaluation of Children's Reading

Achievement. Compiled and Edited by Thomas C. Barrett. Newark, DE: International Reading Association, 1967.

Gutierrez, A. L. Bilingual Education: Reading Through Two Languages. ERIC ED 189-872.

Habecker, James E. An Analysis of Reading Questions in Basal Reading Series Based on Bloom's Taxonomy. (Doctoral Dissertation, University of Pennsylvania) Ann Arbor, MI: University Microfilms, 1976. No. 77-4673.

Hare, Victoria C.. "Beginning Reading Theory and Comprehension Questions in Teachers' Manuals." The Reading Teacher (May 1982), 39-44.

Hare, Victoria C., and Pulliam, Cynthia A. "Teacher Questioning: A Verification and An Extension." Journal of Reading Behavior $12(1980), 69-72$. 
Heilman, Arthur W. Principles and Practices of Teaching Reading. Columbus, OH: Charles E. Merrill, 1972.

Higginbotham, F. W. An Analysis of Content and Methodology for Teaching Critical Reading Skills in Basal Readers. (Doctoral Dissertation, University of Georgia) Ann Arbor, MI: University Microfilms, 1970. No. 71-13.

Hunkins, Francis P. "Analysis and Evaluation Questions: Their Effects Upon Critical Thinking." Educational Leadership 21 (December 1967), 227-34.

Jacobson, M. D. "Predicting Reading Difficulty from Spelling." Spelling Progress Bulletin 14 (1974), 8-10.

Kaluger, George, and Kolson, Clifford. Reading and Learning Disabilities (2nd Ed.). Columbus, $\mathrm{OH}$ : Charles E. Merrill Publishing Company, 1978.

Klare, George R. "Assessing Readability." Reading Research Quarterly $10(1974-75)$, 91-95.

Langan, Yvette. Readability Levels of First and Second Grade Basal Texts (April 1980), ERIC ED 186858, p. 7.

Langer, Judith A. "Levels of Questioning: An Alternative View." Reading Research Quarterly 20, no. 5 (Fall $1985)$, 586-602.

Langer, Susanne. Philosophy in a New Key: A Study in the Symbolism of Reason, Rite and Art. MA: Harvard University Press, 1951.

Lively, B. A., and Pressey, S. L. "A Method for Measuring the 'Vocabulary Burden' of Textbooks." Educational Administration and Supervision 9 (1923), 389-98.

Lorge, Irving. "The Teacher's Task in Development of Thinking." The Reading Teacher 13 (1960), 170-175.

Moore, David W., and Readence, John E. "A Framework for Reading Comprehension Research." Journal of Research and Development in Education, 17(1) (1983), 12-19.

Pearson, David P. "Changing the Face of Reading Comprehension Instruction." The Reading Teacher (April $1985), 724-38$.

Pearson, David P., and Johnson, Dale. Teaching Reading Comprehension. New York: Holt Rinehart and Winston, 1972 . 
Pearson, P. D., and Gallagher, M. C. "The Instruction of Reading Comprehension." Contemporary Education and Psychology $8(1983), 317-345$.

Purcell, B. H. "Methods of Teaching Reading: A Report on a Tri-State Survey." Elementary School Journal 58 $(1958), 449-453$.

Raphael, Taffy E. "Question-Answering Strategies for Children." The Reading Teacher (November 1982), $186-90$.

Robinson, Helen. Sequential Development of Reading Abilities. Chicago: The University of Chicago Press, 1960 .

Roscoe, John T. Fundamental Research Statistics for the Behavioral Sciences, Second Edition. New York: Holt, Rinehard and Winston, 1975.

Sanders, Norris M. Classroom Questions: What Kinds? New York: Harper \& Row, 1966.

Santos, R. A. Provisions for Critical Reading in Philippine Basal Readers: An Analysis of Reading Questions Based on a Classification Scheme of Cognitive Skills. (Doctoral Dissertation, Indiana University) Ann Arbor, MI: University Microfilms, 1968. No. 69-6771.

Saville, Muriel R., and Troike, Rudolph C. A Handbook of Bilingual Education. Washington, DC: Teachers of English to Speakers of Other Languages, 1971.

Schreiber, J. E. Teachers' Question-Asking Technigues in Social studies. (Doctoral Dissertation, University of Iowa) Ann Arbor, MI: University Microfilms, 1967. No. 67-9099.

Searfoss, Lyndon W., and Readence, John. Helping Children Learn to Read. Englewood Cliffs, NJ: Prentice Hall, 1985.

Shake, Mary C., and Allington, Richard L. "Where Do Teachers' Questions Come From?" The Reading Teacher (January 1985), 432-38.

Sheldon, W. D. "Pro-Challenger to R. C. Staiger, Basal Reader Programs: How Do They Stand?" In N. B. Smith (Ed.), Current Issues in Reading. Proceedings of the Thirteenth Annual Convention, 13, Part 2. Newark, DE: International Reading Association, 1969. 
Smith, Richard J., and Barrett, Thomas C. Teaching Reading in the Middle Grades. Reading, MA: Addison-Wesley, 1974 .

Spache, George D. The Teaching of Reading. Bloomington, IN: Phi Delta Kappa, 1972.

Spaulding, Seth. "A Spanish Readability Formula." Modern Language Journal 40, no. 8 (December 1956), $433-41$.

SPSSX. Users guide (2nd ed.). Chicago, 1986.

Staiger, R. C. "How Are Basal Readers Used?" Elementary English 35 (1958), 46-49.

Taba, Hilda. Teaching Strategies and Cognitive Functioning in Elementary School Children. San Francisco, CA: San Francisco State College, 1966.

Taba, Hilda, and Elzey, Freeman. "Teaching Strategies and Thought Processes." Teachers College Record LXV (March 1964).

Taba, Hilda; Levine, Samuel; and Elzey, Freeman F. Thinking in Elementary School Children. USOE Cooperative Research Project No. 1574. San Francisco, CA: San Francisco State College, 1964.

Tatham, S. M. "Comprehension Taxonomies: Their Uses and Abuses." The Reading Teacher 32 (November 1978), 190-94.

Thonis, Eleanor w. Teaching Reading to Non-English Speakers. New York: Collier Macmillan International, 1970 .

Thorndike, E. L. The Teacher's Work Book. New York: Teachers College, Columbia University, 1921.

Thorndike, Robert. Reading Comprehension Education in Fifteen Countries. New York: A Halsted Press Book, 1973 .

Tierney, R. J., and Cunningham, J. W. "Research On Teaching Reading Comprehension." In P. H. Pearson (Ed.), Handbook of Reading Research. New York: Longman, 1984 (pp. 609-655). 
Vogue, Mabel, and Washburne, Carleton. "An Objective Method of Determining Grade Placement of Children's Reading Material." Elementary School Journal 28 (1928), 373-81.

Watson, Dorothy. Report Card on Basal Readers. Commission on Reading National Council of Teachers of English. Missouri: University of Missouri, 1987.

Winer, B. J. Statistical Principles in Experimental Design. New York: McGraw-Hill, 1962.

Wolfe, Willavene, and Ellenger, Bernice D. "Teaching Critical Reading: An Observational Study," in Critical Reading, pp. 434-445, edited by Martha L. King, Bernice D. Ellinger, and Willavene Wolfe. Philadelphia: J. B. Lippincott Company, 1967.

Yoakam, Gerald A. Basal Reading Instruction. New York: McGraw-Hill, 1955.

\section{Basal Readers}

Amato, Dolores Rose et al. Spanish Reading Keys. Oklahoma City: The Economy Company, 1980.

Crane, Barbara J. et al. Crane Reading System: Pacer Program. Trenton, NJ: Crane Publishing Company, 1981.

Crane, Barbara J. et al. Spanish Crane Reading System. Trenton, NJ: Crane Publishing Company, 1981.

Matteoni, Louise et al. Economy Reading Series. Oklahoma City: The Economy Company, 1986.

Ramos, Antonio et al. Lectura En Dos Idiomas. Northvale, NJ: Santillana Publishing Company, 1985.

Ramos, Antonio et al. Reading in Two Languages. Northvale, NJ: Santillana Publishing Company, 1985. 
APPENDIX A

The Barrett Taxonomy of Reading Comprehension 


\section{APPENDIX A}

THE BARRETT TAXONOMY

COGNITIVE AND AFFECTIVE DIMENSIONS

$\mathrm{OF}$

READING COMPREHENSION

1.0 Literal Comprehension. Literal comprehension focuses on ideas and information which are explicitly stated in the selection. Purposes for reading and teacher's questions designed to elicit responses at this level may range from simple to complex. A simple task in literal comprehension may be the recognition or recall of a single fact or incident. A more complex task might be the recognition or recall of a series of facts or the sequencing of incidents in a reading selection. Purposes and questions at this level may have the following characteristics.

1.1 Recognition requires the student to locate or identify ideas or information explicitly stated in the reading selection itself or in exercises which use the explicit ideas and information presented in the reading selection. Recognition tasks are: 1.11 Recognition of Details. The student is required to locate or identify facts such as the names of characters, the time of the story, or the place of the story.

1.12 Recognition of Main Ideas. The student is asked to locate or identify an explicit statement in or from a selection which is a main idea of a paragraph or a larger portion of the selection.

1.13 Recognition of a Sequence. The student is required to locate or identify the order of incidents or actions explicitly stated in the selection.

1.14 Recognition of Comparison. The student is requested to locate or identify likenesses and differences in characters, times, and places that are explicitly stated in the selection.

1.15 Recognition of Cause and Effect Relationships. The student in this instance may be required to locate or identify the explicitly stated reasons for certain happenings or actions in the selection. 
1.16 Recognition of Character Traits. The student is required to identify or locate explicit statements about a character which helps to point up the type of person he is.

1.2 Recall requires the student to produce from memory ideas and information explicitly stated in the reading selection. Recall tasks are:

1.21 Recall of Details. The student is asked to produce from memory facts such as the names of characters, the time of the story, or the place of the story.

1.22 Recall of Main Ideas. The student is required to state a main idea of a paragraph or a larger portion of the selection from memory, when the main idea is explicitly stated in the selection.

1.23 Recall of a Sequence. The student is asked to provide from memory the order of incidents or actions explicitly stated in the selection.

1.24 Recall of Comparisons. The student is required to call up from memory the likenesses and differences in characters, times, and places that are explicitly stated in the selection.

1.25 Recall of Cause and Effect Relationships. The student is requested to produce from memory explicitly stated reasons for certain happenings or actions in the selection.

1.26 Recall of Character Traits. The student is asked to call up from memory explicit statements about characters which illustrate the type of persons they are.

2.0 Inferential Comprehension. Inferential comprehension is demonstrated by the student when he uses the ideas and information explicitly stated in the selection, his intuition, and his personal experience as a basis for conjectures and hypotheses. Inferences drawn by the student may be either convergent or divergent in nature and the student may or may not be asked to verbalize the rationale underlying his inferences. In general, then, inferential comprehension is stimulated by purposes for reading and teachers' questions which demand thinking and imagination that go beyond the printed page.

2.1 Inferring Supporting Details. In this instance, the student is asked to conjecture about additional facts the author might have included in the selection which would have made it more informative, interesting, or appealing. 
2.2 Inferring Main Ideas. The student is required to provide the main idea, general significance, theme, or moral which is not explicitly stated in the selection.

2.3 Inferring Sequence. The student, in this case, may be requested to conjecture as to what action or incident might have taken place between two explicitly stated actions or incidents, or he may be asked to hypothesize about what would happen next if the selection had not ended as it did but had been extended.

2.4 Inferring Comparisons. The student is required to infer likenesses and differences in characters, times, or places. Such inferential comparisons revolve around ideas such as: "here and there," "then and now," "he and he," "he and she," and "she and she."

2.5 Inferring Cause and Effect Relationships. The student is required to hypothesize about the motivations of characters and their interactions with time and place. He may also be required to conjecture as to what caused the author to include certain ideas, words, characterizations, and actions in his writing.

2.6 Inferring Character Traits. In this case, the student is asked to hypothesize about the nature of characters on the basis of explicit clues presented in the selection.

2.7 Predicting Outcomes. The student is requested to read an initial portion of the selections and on the basis of this reading he is required to conjecture about the outcome of the selection.

2.8 Interpreting Figurative Language. The student, in this instance, is asked to infer literal meanings from the author's figurative use of language.

3.0 Evaluation. Purposes for reading and teacher's questions, in this instance, require responses by the student which indicate that he has made an evaluative judgment by comparing ideas presented in the selection with external criteria provided by the teacher, other authorities, or other written sources, or with internal criteria provided by the reader's experiences, knowledge, or values. In essence evaluation deals with judgment and focuses on qualities of accuracy, acceptability, desirability, worth, or probability of occurrence. Evaluative thinking may be demonstrated by asking the student to make the following judgments. 3.1 Judgments of Reality or Fantasy. Could this really happen? Such a question calls for a judgment by the reader based on his experience. 
3.2 Judgments of Fact or Opinion. Does the author provide adequate support for his conclusions. Is the author attempting to sway your thinking? Questions of this type require the student to analyze and evaluate the writing on the basis of the knowledge he has on the subject as well as to analyze and evaluate the intent of the author.

3.3 Judgments of Adequacy and Validity. Is the information presented here in keeping with what you have read on the subject in other sources? Questions of this nature call for the reader to compare written sources of information, with an eye toward agreement and disagreement or completeness and incompleteness.

3.4 Judgments of Appropriateness. What part of the story best describes the main character? Such a question requires the reader to make a judgment about the relative adequacy of different parts of the selection to answer the question.

3.5 Judgments of Worth, Desirability and Acceptability. Was the character right or wrong in what he did? Was his behavior good or bad? Questions of this nature call for judgments based on the reader's moral code or his value system.

4.0 Appreciation. Appreciation involves all the previously cited cognitive dimensions of reading, for it deals with the psychological and aesthetic impact of the selection on the reader. Appreciation calls for the student to be emotionally and aesthetically sensitive to the work and to have a reaction to the worth of its psychological and artistic elements. Appreciation includes both the knowledge of and the emotional response to literary techniques, forms, styles, and structures.

4.1 Emotional Response to the Content. The student is required to verbalize his feelings about the selection in terms of interest, excitement, boredom, fear, hate, amusement, etc. It is concerned with the emotional impact of the total work on the reader.

4.2 Identification with Characters or Incidents. Teachers' questions of this nature will elicit responses from the reader which demonstrate his sensitivity to, sympathy for, and empathy with characters and happenings portrayed by the author.

4.3 Reactions to the Author's Use of Language. In this instance the student is required to respond to the author's craftsmanship in terms of the semantic dimensions of the selection, namely, connotations and denotations of words. 
4. 4 Imagery. In this instance, the reader is required to verablize his feelings with regard to the author's artistic ability to paint word pictures which cause the reader to visualize, smell, taste, hear, or feel. 
APPENDIX B

Classification of 69 Reading Questions in English 


\section{APPENDIX B}

CLASSIFICATION OF 69 READING QUESTIONS IN ENGLISH BY THREE RATERS AND RESEARCHER USING THE BARRETT TAXONOMY

\begin{tabular}{|c|c|c|c|c|c|}
\hline \multirow{2}{*}{$\begin{array}{l}\text { Question } \\
\text { Number }\end{array}$} & \multicolumn{5}{|c|}{ Classification* } \\
\hline & Rater A & Rater & B Rater C & Researcher & \\
\hline 1 & 1 & 1 & 1 & 1 & ** \\
\hline 2 & 1 & 2 & 1 & 1 & \\
\hline 3 & 1 & 1 & 1 & 1 & $* *$ \\
\hline 4 & 1 & 1 & 1 & 1 & $* *$ \\
\hline 5 & 1 & 1 & 1 & 1 & ** \\
\hline 6 & 1. & 1 & 1 & 1 & $* *$ \\
\hline 7 & 1 & 1 & 1 & 1 & $* *$ \\
\hline 8 & 1 & 1 & 1 & 1 & $* *$ \\
\hline 9 & 1 & 1 & 1 & 1 & $* *$ \\
\hline 10 & 1 & 1 & 1 & 1 & $* *$ \\
\hline 11 & 1 & 1 & 1 & 1 & $* *$ \\
\hline 12 & 1 & 1 & 1 & 1 & $* *$ \\
\hline 13 & 3 & 2 & 1 & 1 & \\
\hline 14 & 3 & 2 & 4 & 3 & \\
\hline 15 & 2 & 2 & 2 & 2 & $* *$ \\
\hline 16 & 1 & 1 & 1 & 1 & $* *$ \\
\hline 17 & 2 & 2 & 2 & 2 & $* *$ \\
\hline 18 & 1 & 1 & 1 & 1 & $* *$ \\
\hline 19 & 1 & 1 & 1 & 1 & $* *$ \\
\hline 20 & 1 & 1 & 1 & 1 & $* *$ \\
\hline 21 & 4 & 4 & 4 & 4 & $* *$ \\
\hline 22 & 1 & 1 & 1 & 1 & $* *$ \\
\hline
\end{tabular}

*This table is to be read as follows: The figures in the first column represent the number of the reading question as it appeared in the sample classified. The figures under each of the judges' and researcher's columns represent the categories as (1) Literal, (2) Inferential, (3) Evaluation, and (4) Appreciation.

**All judges agreed with the researcher's classification. 
CLASSIFICATION OF 69 READING QUESTIONS

(Continued)

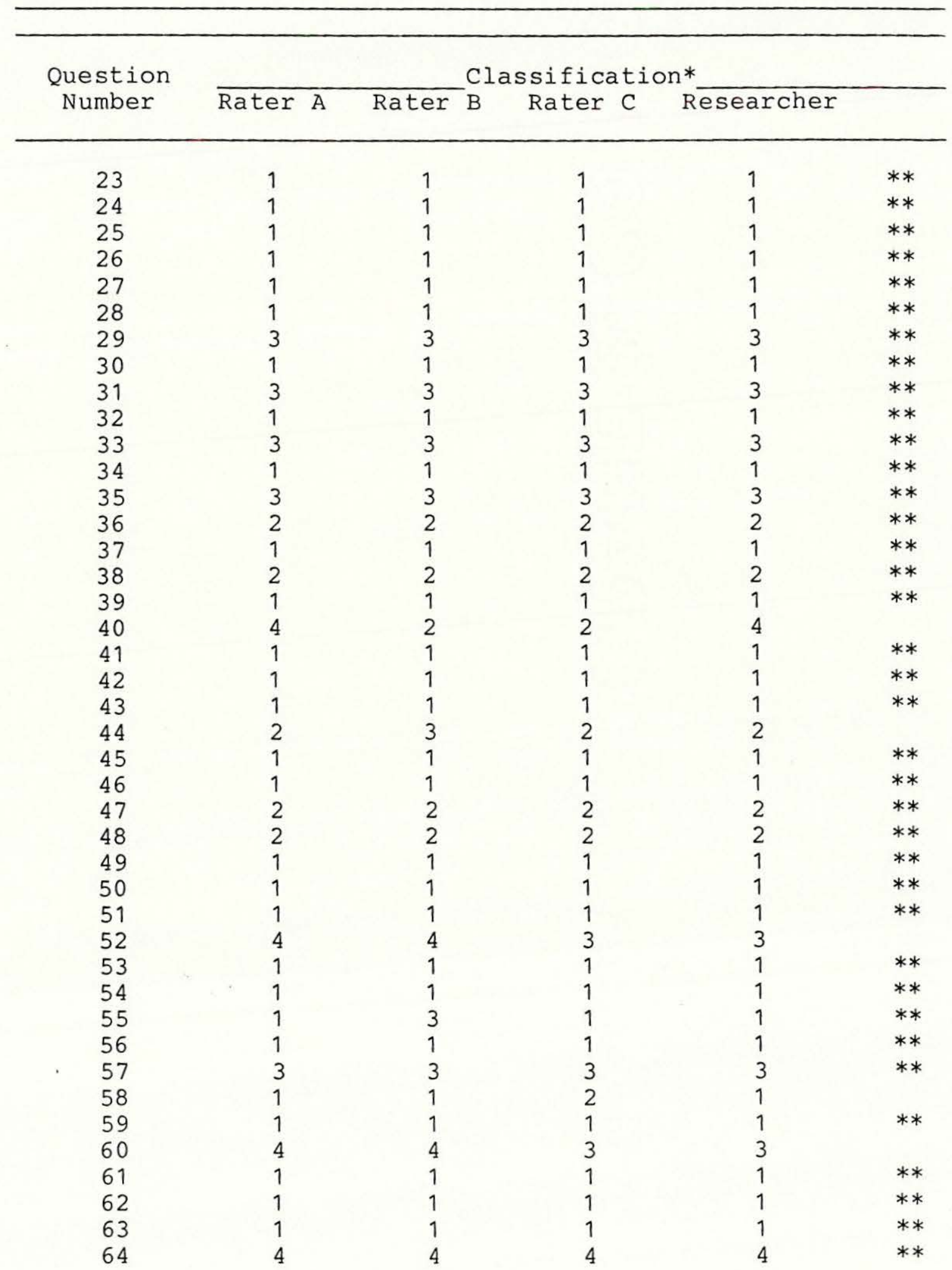


CLASSIFICATION OF 69 READING QUESTIONS (Continued)

Question Classification*

Number Rater A Rater B Rater C Researcher

65

67

68

69

$\begin{array}{ll}1 & 1 \\ 4 & 4 \\ 4 & 4 \\ 3 & 3 \\ 4 & 4\end{array}$

1
4
4
3
4

1

4

3

4 


\section{APPENDIX C}

Classification of 63 Reading Questions in Spanish 
APPENDIX C

CLASSIFICATION OF 63 READING QUESTIONS

IN SPANISH BY THREE RATERS AND RESEARCHER

USING THE BARRETT TAXONOMY

\begin{tabular}{|c|c|c|c|c|c|}
\hline \multirow{2}{*}{$\begin{array}{c}\text { Question } \\
\text { Number }\end{array}$} & \multicolumn{5}{|c|}{ Classification* } \\
\hline & Rater A & Rater & B Rater C & Researcher & \\
\hline 1 & 1 & 1 & 1 & 1 & $* *$ \\
\hline 2 & 1 & 1 & 1 & 1 & $* *$ \\
\hline 3 & 2 & 2 & 2 & 2 & $* *$ \\
\hline 4 & 2 & 3 & 2 & 2 & \\
\hline 5 & 2 & 2 & 2 & 2 & $* *$ \\
\hline 6 & 1 & 1 & 1 & 1 & $* *$ \\
\hline 7 & 1 & 1 & 1 & 1 & $* *$ \\
\hline 8 & 2 & 3 & 2 & 2 & \\
\hline 9 & 2 & 2 & 2 & 2 & $* *$ \\
\hline 10 & 4 & 4 & 4 & 4 & $* *$ \\
\hline 11 & 1 & 2 & 1 & 1 & \\
\hline 12 & 1 & 1 & 1 & 1 & $* *$ \\
\hline 13 & 3 & 3 & 3 & 3 & $* *$ \\
\hline 14 & 2 & 2 & 2 & 2 & $* *$ \\
\hline 15 & 3 & 3 & 3 & 3 & $* *$ \\
\hline 16 & 3 & 2 & 2 & 2 & \\
\hline 17 & 1 & 1 & 1 & 1 & $* *$ \\
\hline 18 & 1 & 1 & 1 & 1 & $* *$ \\
\hline 19 & 1 & 1 & 1 & 1 & $* *$ \\
\hline 20 & 3 & 3 & 3 & 3 & $* *$ \\
\hline 21 & 1 & 1 & 1 & 1 & $* *$ \\
\hline 22 & 1 & 1 & 1 & 1 & $* *$ \\
\hline 23 & 1 & 1 & 1 & 1 & $* *$ \\
\hline 24 & 1 & 1 & 1 & 1 & $* *$ \\
\hline
\end{tabular}

*This table is to be read as follows: The figures in the first column represent the number of the reading question as it appeared in the sample classified. The figures under each of the judges' and researcher's columns represent the categories as (1) Literal, (2) Inferential, (3) Evaluation, and (4) Appreciation.

**All judges agreed with the researcher's classification. 
CLASSIFICATION OF 63 READING QUESTIONS

(Continued)

\begin{tabular}{|c|c|c|c|c|c|}
\hline \multirow{2}{*}{$\begin{array}{l}\text { Question } \\
\text { Number }\end{array}$} & \multicolumn{5}{|c|}{ Classification* } \\
\hline & Rater A & Rater & Rater C & Researcher & \\
\hline 25 & 1 & 1 & 1 & 1 & $* *$ \\
\hline 26 & 1 & 1 & 1 & 1 & $* *$ \\
\hline 27 & 1 & 1 & 1 & 1 & $* *$ \\
\hline 28 & 1 & 1 & 1 & 1 & $* *$ \\
\hline 29 & 1 & 1 & 1 & 1 & $* *$ \\
\hline 30 & 1 & 1 & 1 & 1 & $* *$ \\
\hline 31 & 1 & 1 & 1 & 1 & $* *$ \\
\hline 32 & 1 & 1 & 1 & 1 & $* *$ \\
\hline 33 & 1 & 1 & 1 & 1 & $* *$ \\
\hline 34 & 1 & 1 & 1 & 1 & $* *$ \\
\hline 35 & 1 & 1 & 1 & 1 & $* *$ \\
\hline 36 & 1 & 3 & 3 & 3 & \\
\hline 37 & 4 & 4 & 4 & 4 & $* *$ \\
\hline 38 & 1 & 1 & 1 & 1 & $* *$ \\
\hline 39 & 2 & 3 & 3 & 3 & \\
\hline 40 & 4 & 4 & 4 & 4 & $* *$ \\
\hline 41 & 4 & 4 & 4 & 4 & $* *$ \\
\hline 42 & 3 & 3 & 3 & 3 & $* *$ \\
\hline 43 & 1 & 1 & 1 & 1 & $* *$ \\
\hline 44 & 1 & 1 & 1 & 1 & $* *$ \\
\hline 45 & 4 & 4 & 4 & 4 & $* *$ \\
\hline 46 & 1 & 2 & 2 & 2 & \\
\hline 47 & 4 & 4 & 4 & 4 & $* *$ \\
\hline 48 & 4 & 4 & 3 & 3 & \\
\hline 49 & 3 & 3 & 3 & 3 & $* *$ \\
\hline 50 & 2 & 2 & 2 & 2 & $* *$ \\
\hline 51 & 1 & 1 & 1 & 1 & $* *$ \\
\hline 52 & 2 & 2 & 2 & 2 & $* *$ \\
\hline 53 & 3 & 3 & 3 & 3 & $* *$ \\
\hline 54 & 3 & 3 & 3 & 3 & $* *$ \\
\hline 55 & 1 & 1 & 1 & 1 & $* *$ \\
\hline 56 & 2 & 2 & 2 & 2 & $* *$ \\
\hline 57 & 3 & 2 & 2 & 2 & \\
\hline 58 & 1 & 1 & 1 & 1 & $* *$ \\
\hline 59 & 3 & 3 & 3 & 3 & $* *$ \\
\hline 60 & 4 & 4 & 4 & 4 & $* *$ \\
\hline 61 & 3 & 3 & 3 & 3 & $* *$ \\
\hline 62 & 3 & 3 & 3 & 3 & $* *$ \\
\hline 63 & 4 & 4 & 4 & 4 & $* *$ \\
\hline
\end{tabular}


APPENDIX D

Basal Readers Selected for Study 
APPENDIX D

BASAL READERS SELECTED FOR THE STUDY

ECONOMY COMPANY - SPANISH READING KEYS

$\begin{array}{lll}\text { Hasta Luego } & \text { First Reader } & \text { 1st } \\ \text { Mi Mundo } & \text { Reader } & \text { 2nd } \\ \text { Nuestra Alegria } & \text { Reader } & \text { 2nd } \\ \text { Mi Rincon } & \text { Reader } & \text { 3rd }\end{array}$

ECONOMY COMPANY - ECONOMY READING SERIES

$\begin{array}{ll}\text { Sunshine Day } & 1 \text { st } \\ \text { Crystal Forest } & 2.1 \\ \text { Spring Flight } & 2.2 \\ \text { New Leaves } & 3.1 \\ \text { Bright Wonders } & 3.2 \\ \text { Silver Rain } & 4\end{array}$

SANTILLANA - LECTURA EN DOS IDIOMAS

$\begin{array}{lll}\text { Cascabel } & \text { Preprimer 1 } & \text { 1st } \\ \text { Trampolin } & \text { Preprimer 2 } & \text { 1st } \\ \text { Umbral } & \text { Preprimer 3 } & 1 \text { st } \\ \text { Rayuela } & \text { Reader 1 } & \text { 2nd } \\ \text { Adelante } & \text { Reader 2 } & \text { 3rd }\end{array}$

SANTILLANA - READING IN TWO LANGUAGES

$\begin{array}{lll}\text { Discovering } & \text { Preprimer 1 } & \text { 1st } \\ \text { Imagining } & \text { Preprimer 2 } & \text { 1st } \\ \text { Navigating } & \text { Preprimer 3 } & \text { 1st } \\ \text { Galloping } & \text { Reader 1 } & \text { 2nd } \\ \text { Lickety-Split } & \text { Reader 2 } & \text { 3rd }\end{array}$

CRANE - SPANISH CRANE READING SYSTEM

Suenos Y Aventuras

Visiones Y Pensamientos

Esperanzas $Y$ Alegrias
Level III $1 \mathrm{st}$

Level IV 2nd

Level $\mathrm{V} 3 \mathrm{rd}$ 
CRANE - CRANE READING SYSTEM: PACER PROGRAM

$\begin{array}{ll}\text { Treasures } & 1 \text { st } \\ \text { Magic Moments } & 2.1 \\ \text { New World } & 2.2 \\ \text { Open Spaces } & 3.2 \\ \text { Growing Circles } & 3.2\end{array}$


APPENDIX E

Stories Selected for Study 
APPENDIX E

STORIES SELECTED FOR STUDY BY GRADE LEVEL

\section{SANTILLANA - LECTURA EN DOS IDIOMAS}

1st Grade

-.- Mi Mono

-.- El Dedal De Dina

- El Pirata Peralo

-.- Paula Va Al Doctor

--- El Mago Merengue

-.- En La Kermesse

2nd Grade

-.- Pinocho Va a La Escuela

-.- Bartolo Sale al Camino

--- Por Que Hay un Puente Que se Llama Kate Shelley

-.- Una Gran Aventura en el Espacio

--- Un Marino que se Llama Colon

--- Caracol, abre la puerta que sale el sol!

3rd Grade

-.- Rumbo a La Isla

-.- Alegria

-.- De Semilla a Arbol

--- El Semafaro Que No Queria Ser Semafaro

--- Valentina No Camina

--- Una Carta Para Mis Amigos

SANTILLANA - READING IN TWO LANGUAGES

1st Grade

--- My Monkey

-.- Bim and Mimi and the Banana

--- The Tiger and The Men

--- Hopping Tilly!

-.- Picnic Fun

-.. All the way to School

2nd Grade

-.- Cold Weather

--- The Hippopotamus Gets a Home

-.- Find a Way!

-.- Ant Work

--- Looking for a Shape

--- Country Land and City Land 
3rd Grade

--- Dinner in the Woods

--- Flashlight Kitten

--- Watertown Without Music

-.- New Year's Day

--- Birthday Game

-.- Angel Cordero in the Winner's Circle

ECONOMY COMPANY - SPANISH READING KEYS

1 st Grade

--- Los Viajes del Senor de Los Titeres

-.- Buenos Amigos

-- Ropa para la Fiesta

-.- El Regalo

-.- Un Equipo

--- Reportando las Noticias

2nd Grade

--- Un Deseo

--- Senales de Seguridad

-.- Dias de Fiesta

--- El Conejo Bionico

--- El Estornudo Fuerta

--- Ensenandose el uno al Otro

3rd Grade

-.- Patines de Rueda

-.- Carlitos el Bonachon

-- Baleros, Canicas y Matatenas

--- El Bigote de Don Mariano

--- Companeros del Sol

--- La Vibora Ingrata

ECONOMY COMPANY - READING SERIES

1 st Grade

--- Clouds Can Be Many Things

--- The Boy who Painted Cats

--- The Country Mouse and the City Mouse

-.- The Ant and the Dove

--- The Boy who Cried "Wolf"

--- Farming

2nd Grade

--- My Friend William Moved Away

-.- The Case of the Missing Code Book

-.- A New Language for Pablo/The New Home

--- Worthington Botts and the Steam Machine

--- Why the Bear Has a short Tail

-.- Penelope Gets Wheels 
3rd Grade

-- What's the Matter with Carruthers?

--- Flat Stanley

-.- Benny's Flag

--- Home-run Hannibal

-.- Marie Curie

-.- Oz, the Great and Terrible

4th Grade

--- Melindy's Medal

--- The Treasure of Sumiko's Bay

--- Thank You, Jackie Robinson

--- City Hall

--- The Case of the Treasure Map

--- The Long Winter

CRANE - SPANISH CRANE READING SYSTEM

1 st Grade

--- La Casa Vieja

-.- Las Aventuras de Pancho

-.- Llegan del Campo

.-- En el Camino

-.- Los Caballitos

-.- Corre y Corre

2nd Grade

-.- Se Van en Avion

-.- Jose de Diego

-.- El Soldado de Plomo

-.- El Cuento de Aurelio

-.- El Correcaminos

-.- El Diario Perdido

3rd Grade

--- El Hombrecito

-.- Formidable

-.- El Robo en el Museo

-.- El Pino

-.- Simon Bolivar

-.- Botellas Mensajeras

CRANE - CRANE READING SYSTEM: PACER PROGRAM

1st Grade

--- The Apple and the Ax

-.- I'm Late

--- Over the Top 
2nd Grade

--- Only for a Day

-.- The Race

-.- Why the Sea Is Salty

--- The Case of the Missing Treat

-.- The Birthday Surprise

-.- A Strange Sea Animal

3rd Grade

--- Magic on the Rooftop

--- Summer in Alaska

--- Many Thousands Gone!

--- The Spaceship

--- Amelia Earhart: First Woman of Flight

-.- Ferinand Magellan: A World Explorer 